\title{
Advances in Macroeconomics
}

Volume 6, Issue 1

\section{Inflation, Prices, and Information in Competitive Search}

\author{
Miquel Faig* $\quad$ Belén Jerez ${ }^{\dagger}$
}

*University of Toronto, mfaig@ @ chass.utoronto.ca

†Universidad Carlos III de Madrid, mjerez@eco.uc3m.es

Copyright (c)2006 The Berkeley Electronic Press. All rights reserved. 


\title{
Inflation, Prices, and Information in Competitive Search*
}

\author{
Miquel Faig and Belén Jerez
}

\begin{abstract}
We study the effects of inflation in a competitive search model where each buyer's utility is private information, and money is essential. The equilibrium is efficient at the Friedman rule, but inflation creates an inefficiency in the terms of trade. Buyers experience a preference shock after they are matched with a seller, and thus they have a precautionary motive for holding money. Sellers, who compete to attract buyers, post non-linear price schedules. As inflation rises, sellers post relatively flat price schedules, which reduce the need for precautionary balances. These price schedules induce buyers with a low desire to consume to purchase inefficiently high quantities because of the low marginal cost of purchasing goods. In contrast, buyers with a high desire to consume purchase inefficiently low quantities as they face binding liquidity constraints. The model fits historical US data on velocity and interest rates.
\end{abstract}

KEYWORDS: inflation, precautionary money demand, competitive search, private information

*Faig: Department of Economics, University of Toronto, 150 St. George Street, Toronto, Canada, M5S 3G7. E-mail: mfaig@ @hass.utoronto.ca. Jerez: Departamento de Economía, Universidad Carlos III de Madrid, 28903 Getafe, Spain. E-mail: mjerez@eco.uc3m.es. We are grateful to John Leahy and two anonymous referees for very helpful comments and suggestions. The revised draft was completed while Jerez was visiting the University of Pennsylvania. We thank this institution for its kind hospitality. We also thank Yan Bai, Ken Burdett, Ricardo Cavalcanti, Andrés Erosa, Berthold Herrendorf, Gueorgui Kambourov, Guido Menzio, Joe Ostroy, Víctor Ríos-Rull, Guillaume Rocheteau, and Randall Wright, and participants at the SED in Budapest, the Universities of Toulouse, UCLA, Oregon, Toronto, Penn, Paris I, Carlos III, and Málaga, and the Cleveland Fed. Financial support from Fundación Ramón Areces, Comunidad de Madrid (project 06HSE01752004), and Spanish DGCYT (project SEJ2004-07861 and Ramón y Cajal Program) and SSHRC of Canada is gratefully acknowledged. Any errors are ours. 
Faig and Jerez: Inflation, Prices, and Information in Competitive Search

\section{Introduction}

Since the seminal work of Kiyotaki and Wright $(1989,1991)$, monetary search models have become the dominant paradigm in monetary theory. The central assumption in these models is that trade is bilateral and anonymous, and enforcement is limited. Since a double coincidence of wants is rare in bilateral trade, this implies that money is essential in facilitating transactions. ${ }^{1}$ Another important assumption in these models is that the terms of trade are determined through bargaining under full information. We think that there is a tension between these two assumptions: on the one hand, trade is modelled as anonymous and, on the other hand, the traders perfectly observe each others' preferences.

In this paper, we propose an alternative environment that avoids this tension. The key features of this environment are as follows. First, we maintain the central assumption that the trading process is decentralized and anonymous, and enforcement is limited, so money plays an essential role in facilitating transactions. Second, buyers have heterogeneous valuations for the sellers' goods. Specifically, due to a random component of the search process, buyers sometimes find goods that have high value for them, while at other times they find goods that they do not value much. For instance, buyers' valuations may depend on certain idiosyncratic characteristics of the sellers' product that can only be verified by visiting a store to try on a pair of pants, for example, or taste specific items in a restaurant's menu. To capture this feature, we introduce a preference shock that hits buyers after they have both decided the demand for money and been matched with a seller. Third, buyers have private information about how much they value goods as a result of the realization of the preference shock. Finally, the search process is competitive. This means that, prior to matching, sellers post price offers that specify the terms at which they commit to trade. Buyers then observe all the posted offers and direct their search to the sellers who post the most attractive offer for them. ${ }^{2}$

The effects of inflation in our model are quite different from earlier monetary search models. We show that inflation distorts individuals' decisions by inducing some of them to purchase and consume goods they would otherwise not consume. These individuals make such inefficiently high purchases in order to spend their money fast and avoid the inflation tax.

Preference shocks, their timing, and their privately observed nature are the fea-

1 The idea that the role for money arises from the difficulties of barter exchange goes back to Jevons and other classical writers. Earlier formalizations of this old idea go back to Ostroy (1973), who emphasizes that restrictions in terms of resources, information and enforcement that characterize bilateral exchange. See also Kocherlakota (1998) and Wallace (2001).

2 The concept of competitive search with infinitesimal traders was introduced by Moen (1997) and Shimer (1996) in the context of the labor market following up earlier work by Peters (1991) and Montgomery (1991) with a finite number of traders. Recently, Rocheteau and Wright (2005) introduced this concept in monetary search theory. 
tures of the environment that are most crucial for our results. With these features we seek to capture two characteristics typical of retail markets. The first one is that buyers usually face uncertain expenditure needs. Since money is essential in some transactions, this uncertainty implies that buyers have a precautionary motive for holding money. The second characteristic is that sellers face a potential clientele of buyers with different valuations for the products they sell. This characteristic is important because it allows sellers to use pricing schemes that involve cross-subsidization among buyers with different valuations, so it is possible that in equilibrium some buyers end up purchasing inefficiently high quantities. Because sellers cannot observe the valuations of buyers in our model, their pricing schemes are restricted to satisfy incentive-compatibility constraints. As is standard in the mechanism-design literature, sellers use non-linear price schedules to screen out different types of buyers. ${ }^{3}$ With constant returns in production, these price schedules implicitly give quantity discounts to buyers. These discounts are common in retail trade where we observe deals of the sort, "Pay for two and get three," and we observe packaging that reduces per-unit prices in large purchases (the larger the pizza, the lower the price of a slice).

The intuition for the market distortions caused by inflation in our model is as follows. With inflation, buyers have an incentive to reduce their money balances. Sellers, who are aware of this and compete against each other to attract buyers, react by posting price schedules that are flatter than the variable cost of production. These price schedules are attractive for buyers because they reduce the variance of payments and hence the need for precautionary money balances. Crucially, however, these price schedules also reduce the marginal cost of additional purchases. As a result, buyers with low realizations of the preference shock end up consuming inefficiently high quantities. Meanwhile, buyers with high realizations of the preference shock consume inefficiently low quantities because they face binding liquidity constraints. The overall effect of inflation is then to reallocate goods from buyers with high marginal utilities to buyers with low marginal utilities, which is clearly an inefficiency. A positive opportunity cost of holding money is crucial to this argument. If there is no opportunity cost of holding money or, equivalently, if individuals can avoid this cost completely using alternative means of payment such as credit, ${ }^{4}$ the competitive search mechanism internalizes the search externalities. In this case, sellers post price schedules that reflect the cost of production, so the

\footnotetext{
3 See Mussa and Rosen (1978) and Maskin and Riley (1984) who analyze the problem of a monopolistic seller who faces no price competition.

4 In reality, buyers can use credit to reduce the need for precautionary balances. However, if credit could be costlessly used in all transactions, the demand for money would disappear. Our results are robust to credit being available for some transactions, but not for others. In a companion paper (Faig and Jerez (2005b)), we consider a variant of the model along these lines.
} 
Faig and Jerez: Inflation, Prices, and Information in Competitive Search

first best is attained under the Friedman rule. ${ }^{5}$

The key positive result of our model is that the demand for money is interest elastic. An increase in the nominal interest rate increases the opportunity cost of holding money relative to other assets, so it has a negative impact on the demand for money. In addition to this standard direct effect, there is an indirect general equilibrium effect as the equilibrium price schedule adjusts and becomes flatter. This price adjustment reduces the probability that buyers are left with unspent balances each period. While the demand for money falls in equilibrium, the decrease is lower because of the price adjustment. The combined effect is then that buyers hold lower money balances and that money circulates faster. The model is able to fit historical data from the United States on the velocity of the circulation of money and nominal interest rates, without generating counterfactual predictions on the composition of GDP or the length of the payments period. With the estimated parameters, we find that the welfare cost of inflation is approximately 0.5 per cent of GDP, which matches the area below the predicted money demand curve.

The idea that inflation provides incentives to change trading arrangements in order to avoid idle or precautionary money balances is also found in two recent papers. In Faig and Huangfu (2006), inflation gives market-makers an incentive to intermediate between buyers and sellers with the objective of eliminating idle money balances. In Berentsen, Camera, and Waller (2005), inflation gives banks a similar incentive to do such intermediation. In our model, there is no intermediation between buyers and sellers from any third party. Instead, it is the pricing mechanism that adjusts in order to reduce the need for idle money balances. Our model is also related to that of Lagos and Rocheteau (2005) in which moderate inflation rates induce buyers to search more intensively when search is competitive. Instead of searching more intensively, here buyers avoid the inflation tax by buying larger quantities each time they shop. In general, the consequences of inflation in our model are quite different from these earlier models. In particular, the reallocation of goods from individuals with high valuations to individuals with low valuations is a novelty of our model.

As we have already noted, the key theoretic novelty of the paper is to introduce private information over preferences in monetary search models. We follow our treatment of private information in Faig and Jerez (2005a) where we study a competitive search model of commerce in a non-monetary economy. The introduction of private information both in monetary models and competitive search models is a natural development which is gaining momentum. Williamson and Wright (1994), Camera and Winkler (2002), Berentsen and Rocheteau (2004) and Ennis (2005) in-

5 That is, the incentive compatibility constraints do not bind. In general, the revelation of private information creates welfare costs (see Faig and Jerez (2005a) for an example). In our model these costs can be avoided because, in addition to the cost of production, sellers can charge a flat fee to buyers which remunerates the cost of their labor. 
troduce private information in monetary models, but they assume that the terms of trade are determined through bargaining rather than through competitive search. In particular, Ennis (2005) considers a similar monetary environment where buyers' preferences are private information, but he assumes that sellers have all the bargaining power. Shimer and Wright (2004), Moen and Rosen (2004), and Guerrieri (2005) recently introduce private information in competitive search models of the labor market.

In a related paper (Faig and Jerez (2005b)), we also argue that the precautionary demand for money explains well the dynamics of the historical velocity of the circulation of money in the United States. The model in that paper simplifies the effect of inflation on the terms of trade, which we study here, by assuming that preference shocks are realized after buyers decide their demand for money but prior to matching. With the different timing, sellers are able to post price offers that target particular buyer types. In competitive search equilibrium, buyers are then separated in different submarkets according to their type, so the possibility of crosssubsidization emphasized here is eliminated.

The structure of the paper is as follows. Section 2 describes the environment, which extends the framework of Lagos and Wright (2005) to allow for competitive search and private information. Sections 3 and 4 characterize the competitive search equilibrium with full and private information, respectively. Section 6 concludes. The proofs are gathered in the Appendix.

\section{The Environment}

There is a continuum of ex-ante identical individuals with measure one. Time is infinite and discrete. As in Lagos and Wright (2005), each period consists of two subperiods, day and night, during which the market structure differs.

During the day, individuals produce and consume goods that are traded in Walrasian markets, and at night individuals trade bilaterally in search markets. There is another object, called money, which is intrinsically useless, perfectly divisible, and storable. Units of money are called dollars. We assume that individuals can either be buyers (consume) or sellers (produce) in the search night market, and that they must choose their trading role at the start of each period. One may think, for example, that buyers and sellers must perform distinct preparatory tasks during the day in order to trade at night. ${ }^{6}$ The ex-ante choice of trading roles generates a simple double-coincidence problem which makes money essential in the search market, because buyers are anonymous and enforcement is limited.

The timing of a typical period is as follows. Early in the day, the government hands out monetary transfers that increase the money supply. Individuals then de-

6 A similar choice is present in Rocheteau and Wright (2003) and Faig (2004) with slightly different motivations. 
cide whether to be buyers or sellers during the night. Sellers publicly announce offers specifying the terms at which they commit to trade at night. Walrasian markets open, and individuals consume, produce, and adjust their money balances. In particular, buyers need to take money into the night in order to trade, while sellers need no money. When night falls, Walrasian markets close, and the competitive search market opens.

The key assumption in Lagos and Wright's paper (2005) is that agents have identical quasi-linear preferences over the goods traded in Walrasian markets. This assumption is particularly useful because it implies that all individuals who choose to be buyers in a given period enter the search market with identical money holdings. (Individuals who choose to be sellers enter this market with no money). Therefore, the distribution of money holdings in the search market is degenerate, which makes the model analytically tractable and allows for simple closed-form solutions. ${ }^{7}$ The day period instantaneous utility of an individual is

$$
v\left(x_{t}\right)-y_{t}
$$

where $x_{t}$ and $y_{t}$ are respectively consumption and production during the day. The key assumption, as noted above, is that utility is linear on $y_{t}$.

The night period instantaneous utility of an individual depends on the choice of trading role. The utility of an individual who chooses to be a buyer in the night of date $t$ is

$$
\mathcal{U}^{b}\left(q_{t} ; \varepsilon_{t}\right)=\varepsilon_{t} u\left(q_{t}\right),
$$

where $q_{t}$ is consumption at night. The key assumption here is that the utility from consumption at night depends on an idiosyncratic match-specific preference shock $\varepsilon_{t}$ which is realized the moment the buyer is matched with a seller. Since buyers decide their money demand before the realization of the shock, they have a precautionary motive for holding money. The preference shock is uniformly distributed in the interval $[1, \bar{\varepsilon}]$, independent across time, and drawn in such a way that the Law of Large Numbers holds across individuals. The cumulative distribution function is then

$$
F(\varepsilon)=\varphi(\varepsilon-1),
$$

where $\varphi$ represents the constant density: $\varphi=(\bar{\varepsilon}-1)^{-1}$. Similarly, the night period payoff of an individual who chooses to be a seller is

$$
\mathcal{U}^{s}\left(q_{t}\right)=-c\left(q_{t}\right)
$$

where $c\left(q_{t}\right)$ denotes the disutility from production at night.

7 Shi (1997) and Faig (2004) propose alternative frameworks that simplify the distribution of money holdings. We use Lagos and Wright's (2005) framework because it is simpler and may be more intuitive. However, the results in this paper do not depend on the particular framework used. 
Individuals seek to maximize their lifetime expected utility:

$$
E \sum_{t=0}^{\infty} \beta^{t}\left[v\left(x_{t}\right)-y_{t}+\mathcal{U}^{j(t)}\right]
$$

where $\beta \in(0,1)$ is the discount factor, and $j(t) \in\{b, s\}$ is the trading role chosen in the night of date $t .{ }^{8}$ We assume $v, u$ and $c$ are continuously differentiable and strictly increasing, $v$ and $u$ are strictly concave, and $c$ is convex, with $u(0)=c(0)=0$, and $c^{\prime}(0)<u^{\prime}(0)=v^{\prime}(0)=\infty$. Also, there is a set of positive numbers $\left\{x^{*},\left\{q_{\varepsilon}^{*}\right\}_{\varepsilon \in[1, \bar{s}]}\right\}$ such that $v^{\prime}\left(x^{*}\right)=1$ and $\varepsilon u^{\prime}\left(q_{\varepsilon}^{*}\right)=c^{\prime}\left(q_{\varepsilon}^{*}\right)$.

The supply of money grows at a constant factor $\gamma$, so

$$
M_{t+1}=\gamma M_{t},
$$

where $M_{t}$ is the quantity of money per capita. Each day new money is injected via a lump-sum transfer $\tau_{t}$ common to all individuals:

$$
\tau_{t}=(\gamma-1) M_{t}
$$

We shall restrict attention to policies that satisfy $\beta<\gamma<\beta(1+\bar{\varepsilon}) / 2$. The condition $\beta<\gamma$ ensures that there is a positive opportunity cost of holding money, and the condition $\beta(1+\bar{\varepsilon}) / 2$ ensures existence of the type of monetary equilibria we analyze. ${ }^{9}$

To complete the description of the environment, we need to describe how the terms of trade are determined in the night market. At night, goods are traded in a competitive search market, as in Moen (1997) and Shimer (1996). Prior to the search process, each seller simultaneously posts an offer that specifies the terms at which they commit to trade. Specifically, an offer is a schedule $\left\{q_{t \varepsilon}, d_{t \varepsilon}\right\}_{\varepsilon \in[1, \bar{\varepsilon}]}$ specifying the quantity traded $q_{t \varepsilon}$ and the total payment in dollars $d_{t \varepsilon}$ conditional on the realization of the buyers' preference shock $\varepsilon$ (the buyer's type). Buyers then observe all the posted offers and direct their search towards those sellers posting the most attractive offer (possibly randomizing over offers for which they are indifferent). The set of sellers posting the same offer and the set of buyers directing their search towards them form a submarket. In each submarket, buyers and sellers meet randomly according to the matching function specified below. When a buyer and a seller meet, the buyer has to either accept the offer $\left\{q_{t \varepsilon}, d_{t \varepsilon}\right\}_{\varepsilon \in[1, \bar{\varepsilon}]}$ and commit to

8 For simplicity, we assume that there is no discount factor between day and the night.

9 In Section 4 we show that, if inflation is sufficiently high $(\gamma>\beta(1+\bar{\varepsilon}) / 2)$, the precautionary demand for money disappears and all buyer types become liquidity constrained at night. In this case, higher inflation reduces the purchases of all buyer types. Here, we focus on monetary equilibria where the lower types are not liquidity constrained, and show that moderate increases in the inflation rate increase the purchases of these types. 
the terms it specifies (say, by making a downpayment), or abandon all trade. If the offer is accepted, the preference shock $\varepsilon$ is then realized and the buyer purchases $q_{t \varepsilon}$ units for $d_{t \varepsilon}$ dollars.

To focus on the pricing issues we are interested in and to avoid unnecessary complications, we assume that individuals experience at most one match and that matching is efficient, meaning that the short-side of the market is always served in each submarket. The probability that a buyer meets a suitable seller is then

$$
\pi^{b}\left(\alpha_{t}\right)=\min \left(1, \alpha_{t}\right)
$$

where $\alpha_{t}$ is the ratio of sellers over buyers in the submarket the buyer chooses to visit. Similarly, the probability that a seller meets a suitable buyer is

$$
\pi^{s}\left(\alpha_{t}\right)=\min \left(1, \alpha_{t}^{-1}\right)
$$

All traders have rational expectations about the mass of buyers that will be attracted by each offer, and hence about the trading probabilities in each submarket.

Table 1: Summary of Activities during a Period

\begin{tabular}{cccccc}
\hline \hline \multicolumn{2}{c}{ DAY } & \multicolumn{3}{c}{ NIGHT } \\
\multicolumn{2}{c}{ Walrasian market is open } & \multicolumn{2}{c}{ Search market is open } \\
\hline transfers & Buyer-seller & Centralized & Buyers & Realization & Bilateral \\
& choice. & trade and & choose & preference & trade \\
& Sellers & choice of & among & shock & \\
& post offers & money & offers & & \\
& & balances & & & \\
\end{tabular}

A typical period proceeds as it is summarized in Table 1. Early in the day, the government hands out monetary transfers that increase the money supply. Individuals then decide whether to be buyers or sellers, and sellers post their offers for the night market. Walrasian markets open, and individuals consume, produce, and adjust their money balances. When night falls, Walrasian markets close, and the competitive search market opens. Submarkets are formed as a result of the competitive search process. When a buyer and a seller meet in a submarket, the buyer chooses whether to accept or reject the offer. If the offer is accepted, the preference shock is realized and the two agents trade according to the pre-specified terms of trade. As a result of trade, sellers produce, buyers consume, and money changes hands from buyers to sellers.

Our equilibrium concept combines perfect competition in the day markets with competitive search at night. In equilibrium, individuals make optimal decisions taking as given the sequence of prices in the Walrasian markets, and the sequence of conditions in the competitive search market to be detailed below (essentially 
the expected reservation surpluses of other traders). Individuals also have rational expectations about how these prices and conditions evolve over time.

\subsection{The Conditional Demand for Money}

This section examines how individuals choose the demand for money in the day market conditional on the submarkets to be visited at night. To this end, we examine the optimal consumption and production decisions during the day, and the choice of trading roles to be performed at night. The next two sections show that all individuals visit the same submarket in equilibrium and solve for the offer sellers choose to post, and the equilibrium ratio of sellers over buyers.

Let $W_{t}^{b}\left(m_{t}\right)$ and $V_{t}^{b}\left(m_{t}\right)$ be the value functions of a buyer with $m_{t}$ dollars when entering the day and the night markets, respectively. Similarly, $W_{t}^{s}\left(m_{t}\right)$ and $V_{t}^{s}\left(m_{t}\right)$ are the corresponding value functions for the seller. Since individuals choose the trading role that yields maximal utility, the value function of an individual with $m_{t}$ dollars at the start of each period is

$$
W_{t}\left(m_{t}\right)=\max \left\{W_{t}^{b}\left(m_{t}\right), W_{t}^{s}\left(m_{t}\right)\right\} .
$$

Let the price of the consumption good in the Walrasian day market be normalized to 1 and denote the price of one unit of money in units of consumption in period $t$ by $\phi_{t}$. In the Walrasian market, the individual solves

$$
W_{t}^{j}\left(m_{t}\right)=\max _{x_{t}, y_{t}, \hat{m}_{t} \geq 0}\left\{v\left(x_{t}\right)-y_{t}+V_{t}^{j}\left(\hat{m}_{t}\right)\right\}
$$

subject to

$$
x_{t}+\phi_{t} \hat{m}_{t}=y_{t}+\phi_{t}\left(m_{t}+\tau_{t}\right) \text {, }
$$

where $j=b$ if he/she chooses to be a buyer and $j=s$ if he/she chooses to be a seller at night. Here, $\hat{m}_{t}$ represents the amount of money the individual carries into the search night market conditional on the occupational decision. ${ }^{10}$ Because utility is quasi-linear, the budget constraint can be substituted into the objective function (11), so that the problem simplifies to ${ }^{11}$

$$
W_{t}^{j}\left(m_{t}\right)=\max _{x_{t}, \hat{m}_{t} \geq 0}\left\{v\left(x_{t}\right)-x_{t}-\phi_{t}\left(\hat{m}_{t}-m_{t}-\tau_{t}\right)+V_{t}^{j}\left(\hat{m}_{t}\right)\right\}, \quad j=b, s .
$$

Thus, it follows that for both buyers and sellers (i) the optimal choice of $x_{t}$ is independent of $m_{t}$ with $v^{\prime}\left(x_{t}\right)=1$, so $x_{t}=x^{*}$; (ii) the optimal choice of $\hat{m}_{t}$ is also independent of $m_{t}$, and maximizes $V_{t}^{j}(\hat{m})-\phi_{t} \hat{m}_{t}$; and (iii) the value functions

10 The choices of $x_{t}, y_{t}$, and $\hat{m}_{t}$ are conditional on $j$, but we omit the superscript to ease notation.

11 One needs to check that the non-negativity constraint on $y_{t}$ is not binding. As in Lagos and Wright (2005), one can derive conditions that guarantee this. 
Faig and Jerez: Inflation, Prices, and Information in Competitive Search

$W_{t}^{j}\left(m_{t}\right)$ are linear in $m_{t}$, with

$$
W_{t}^{j}\left(m_{t}\right)=W_{t}^{j}(0)+\phi_{t} m_{t}, \quad j=b, s .
$$

Finally,

$$
W_{t}\left(m_{t}\right)=\phi_{t} m_{t}+\max \left\{W_{t}^{b}(0), W_{t}^{s}(0)\right\} .
$$

The intuition behind these results is simple. Quasi-linearity implies that the marginal utility of money at the start of the period is constant and equal to $\phi_{t}$ for all individuals. Since there are no wealth effects, no matter what their money holdings are at the start of the period, all buyers choose to carry a quantity of money that maximizes $V_{t}^{b}\left(\hat{m}_{t}\right)-\phi_{t} \hat{m}_{t}$. Similarly, all sellers choose $\hat{m}_{t}$ to maximize $V_{t}^{s}\left(\hat{m}_{t}\right)-$ $\phi_{t} \hat{m}_{t}$.

The value functions of buyers and sellers at night depend on the submarket they visit in equilibrium, and on the money holdings they take into this submarket. For notational convenience we drop the dependence of the value functions on the submarket. Equilibrium will force the value of all active submarkets to be equal. A submarket is characterized by a ratio of sellers over buyers $\alpha_{t}$ and an offer $\left\{q_{t \varepsilon}, d_{t \varepsilon}\right\}_{\varepsilon \in[1, \bar{\varepsilon}]}$. Let $\chi\left(\hat{m}_{t} \geq d_{t \varepsilon}\right)$ denote an indicator function which is equal to one if $\hat{m}_{t} \geq d_{t \varepsilon}$, and is zero otherwise. The Bellman equation for a buyer at night is

$$
\begin{aligned}
V_{t}^{b}\left(\hat{m}_{t}\right)= & \pi^{b}\left(\alpha_{t}\right) \int_{1}^{\bar{\varepsilon}}\left\{\left[\varepsilon u\left(q_{t \varepsilon}\right)+\beta W_{t+1}\left(\hat{m}_{t}-d_{t \varepsilon}\right)\right] \chi\left(\hat{m}_{t} \geq d_{t \varepsilon}\right)\right. \\
& \left.+\left[\pi^{b}\left(\alpha_{t}\right) \chi\left(\hat{m}_{t}<d_{t \varepsilon}\right)+1-\pi^{b}\left(\alpha_{t}\right)\right] \beta W_{t+1}\left(\hat{m}_{t}\right)\right\} d F(\varepsilon) \\
= & \pi^{b}\left(\alpha_{t}\right) \int_{1}^{\bar{\varepsilon}}\left[\varepsilon u\left(q_{t \varepsilon}\right)-\beta \phi_{t+1} d_{t \varepsilon}\right] \chi\left(\hat{m}_{t} \geq d_{t \varepsilon}\right) d F(\varepsilon) \\
& +\beta\left[\phi_{t+1} \hat{m}_{t}+W_{t+1}(0)\right],
\end{aligned}
$$

where we use the fact that $W_{t+1}\left(\hat{m}_{t}\right)$ is linear with slope $\phi_{t+1}$. With probability $\pi^{b}\left(\alpha_{t}\right)$, the buyer meets the seller and, conditional on the realization of the preference shock $\varepsilon$, purchases $q_{t \varepsilon}$ for $d_{t \varepsilon}$ dollars. As a result, the buyer starts the next day with $\hat{m}_{t}-d_{t \varepsilon}$ dollars. Note that the buyer can only trade if he/she holds enough money to meet the required contingent payment: $\hat{m}_{t} \geq d_{t \varepsilon}$. If the buyer does not trade, because he/she does not meet a seller or does meet a seller but does not have enough money to pay, the buyer starts the next day with $\hat{m}_{t}$ dollars.

Combining (13) and (16), and noting that $W_{t+1}(0)$ is independent of $\hat{m}_{t}$, the buyers' optimal demand for money $\hat{m}_{t}$ then solves:

$$
\begin{aligned}
\max _{\hat{m}_{t} \geq 0} \pi^{b}\left(\alpha_{t}\right) \int_{1}^{\bar{\varepsilon}}\left[\varepsilon u\left(q_{t \varepsilon}\right)-\beta \phi_{t+1} d_{t \varepsilon}\right] \chi\left(\hat{m}_{t} \geq\right. & \left.d_{t \varepsilon}\right) d F(\varepsilon) \\
& +\left(\beta \phi_{t+1}-\phi_{t}\right) \hat{m}_{t} .
\end{aligned}
$$


As in Lagos and Wright (2005), the objective of this problem is unbounded (its value goes to infinity as $\left.\hat{m}_{t} \rightarrow \infty\right)$ if $\beta \phi_{t+1}>\phi_{t}$, so there is no solution to (17) in this case. For an equilibrium to exist, the inflation rate must obey $\phi_{t} / \phi_{t+1} \geq \beta$. If $\phi_{t} / \phi_{t+1}>\beta$, the opportunity cost of holding money is strictly positive, and the objective in (17) is decreasing in $\hat{m}_{t}$ for $\hat{m}_{t}>\max \left\{d_{t \varepsilon}\right\}_{\varepsilon \in[1, \bar{\varepsilon}]}$. The value of the objective in (17) under

$$
\hat{m}_{t}=\max \left\{d_{t \varepsilon}\right\}_{\varepsilon \in[1, \bar{\varepsilon}]} .
$$

measures the buyer's expected payoff from trading at night net of the opportunity cost of holding the maximum contingent payment in the submarket the buyer visits. Provided this value is positive and the ex post trade surplus $\varepsilon u\left(q_{t \varepsilon}\right)-\beta \phi_{t+1} d_{t \varepsilon}$ is increasing in the shock realization $\varepsilon$, the demand for money satisfies (18). As we shall see, both conditions will be satisfied in equilibrium. This means that the buyer will always hold just enough money to meet the highest contingent payment. If $\phi_{t} / \phi_{t+1}=\beta$ (Friedman rule), the opportunity cost of holding money is zero and the solution to (18) is not unique. In this case, we pick equilibrium choices that are the limit $\phi_{t} / \phi_{t+1} \downarrow \beta$, so that (18) still holds.

Analogously, the Bellman equation for a seller at night is

$$
\begin{aligned}
V_{t}^{s}\left(\hat{m}_{t}\right)= & \pi^{s}\left(\alpha_{t}\right) \int_{1}^{\bar{\varepsilon}}\left[-c\left(q_{t \varepsilon}\right)+\beta W_{t+1}\left(\hat{m}_{t}+d_{t \varepsilon}\right)\right] d F(\varepsilon) \\
& +\left[1-\pi^{s}\left(\alpha_{t}\right)\right] \beta W_{t+1}\left(\hat{m}_{t}\right) \\
= & \pi^{s}\left(\alpha_{t}\right) \int_{1}^{\bar{\varepsilon}}\left[-c\left(q_{t \varepsilon}\right)+\beta \phi_{t+1} d_{t \varepsilon}\right] d F(\varepsilon) \\
& +\beta\left[\phi_{t+1} \hat{m}_{t}+W_{t+1}(0)\right] .
\end{aligned}
$$

Combining (13) and (19), the optimal choice of $\hat{m}_{t}$ solves $\max _{\hat{m}_{t}}\left(\beta \phi_{t+1}-\phi_{t}\right) \hat{m}_{t}$ subject to $\hat{m}_{t} \geq 0$. Again, this problem has no solution if $\beta \phi_{t+1}>\phi_{t}$, and the solution is $\hat{m}_{t}=0$ if this inequality is reversed. For sellers, money has no value at night, so they optimally choose to carry none.

Collecting (13), (15), (16), (18), (19), and $\hat{m}_{t}=0$ for sellers, the value function at the beginning of the day simplifies into

$$
W_{t}\left(m_{t}\right)=v\left(x^{*}\right)-x^{*}+\phi_{t}\left(m_{t}+\tau_{t}\right)+\beta W_{t+1}(0)+\max \left\{S_{t}^{b}, S_{t}^{s}\right\},
$$

if $\phi_{t} / \phi_{t+1}>\beta$. Here, $S_{t}^{b}$ and $S_{t}^{s}$ represent the expected trade surpluses of a buyer and a seller at night, respectively, which can be written as

$$
\begin{aligned}
S_{t}^{b} & \equiv \pi^{b}\left(\alpha_{t}\right) \int_{1}^{\bar{\varepsilon}}\left[\varepsilon u\left(q_{t \varepsilon}\right)-z_{t \varepsilon}\right] d F(\varepsilon)-i_{t} \hat{z}_{t}, \text { and } \\
S_{t}^{s} & \equiv \pi^{s}\left(\alpha_{t}\right) \int_{1}^{\bar{\varepsilon}}\left[z_{t \varepsilon}-c\left(q_{t \varepsilon}\right)\right] d F(\varepsilon) .
\end{aligned}
$$


In these expressions, $z_{t \varepsilon} \equiv \beta \phi_{t+1} d_{t \varepsilon}$ denotes real payments (discounted units of consumption that can be purchased with $d_{\varepsilon}$ dollars next period). Similarly,

$$
\hat{z}_{t} \equiv \beta \phi_{t+1} \hat{m}_{t}=\max \left\{z_{t \varepsilon}\right\}_{\varepsilon \in[1, \bar{\varepsilon}]}
$$

denotes real money balances conditional on being a buyer, and

$$
i_{t} \equiv \frac{\phi_{t}}{\beta \phi_{t+1}}-1
$$

represents the nominal interest rate. As noted by Lagos and Wright (2005), in this environment the market for bonds features no trade, but bonds can still be priced. The equilibrium real interest rate is equal to the subjective discount rate: $\beta^{-1}-1$. Since the inflation rate is $\pi_{t}=\phi_{t} / \phi_{t+1}-1$, the nominal interest rate satisfies $1+i_{t}=(1+r)\left(1+\pi_{t}\right)=\phi_{t} /\left(\beta \phi_{t+1}\right)$.

In summary, we have shown that an equilibrium cannot exist for inflation rates below the Friedman rule. For inflation rates above the Friedman rule, the individual optimal choices during the day are as follows. Each period $t$, the individual consumes $x_{t}=x^{*}$ and chooses the trading role $j(t) \in\{b, s\}$ for which the expected trade surplus $S_{t}^{j}$ is higher. If the choice is to be a seller, the demand for money is zero. If the choice is to be a buyer, the demand for money is the highest contingent payment in the submarket to be visited at night. Finally, the optimal choices of production $y_{t}$ are given by the budget constraint (12).

\section{Equilibrium with Full Information}

To provide some insight into the competitive search process in our environment and to serve as a benchmark, this section characterizes a monetary equilibrium with full information. Section 4 then characterizes a monetary equilibrium where the preference shock realizations that buyers experience are private information. Both sections focus on stationary monetary equilibria, where aggregate real variables are constant over time (although non-stationary equilibria cannot be ruled out in general). Since real money balances are constant, the gross rate of inflation is equal to the rate of growth of the money supply: $\phi_{t} / \phi_{t+1}=\gamma$. Therefore, the nominal interest rate is $i=(\gamma / \beta)-1$. Since all the variables we analyze are constant, we drop the time subscripts in what follows.

The competitive search process proceeds as follows. Before the search market opens and while buyers can still rebalance the amount of money they hold, sellers

post their offers $\left\{\left(q_{\varepsilon}, z_{\varepsilon}\right)\right\}_{\varepsilon \in[1, \bar{\varepsilon}]}$ (by means of which they commit to sell $q_{\varepsilon}$ units of output in exchange for a real payment $z_{\varepsilon}$ in the event of being matched with a buyer of type $\varepsilon$ ). All individuals have rational expectations regarding the number of buyers that will be attracted by each offer, and thus about the ratio $\alpha$ of sellers over buyers in each submarket. Sellers are also aware that the buyers who decide to trade 
according to a posted offer will carry an amount of money equal to the maximum payment specified in the offer. The set of offers posted in equilibrium must be such that sellers have no incentives to post deviating offers.

Let $\Omega$ be the set of all submarkets that are active in equilibrium. An element $\omega \in \Omega$ is then a list $\omega=\left[\alpha,\left\{\left(q_{\varepsilon}, z_{\varepsilon}\right)\right\}_{\varepsilon \in[1, \bar{\varepsilon}]}\right.$. A competitive search equilibrium at night is a set $\left\{\Omega, \bar{S}^{b}, \bar{S}^{s}\right\}$ such that, for all $\omega \in \Omega$,

1. Buyers attain the same expected surplus $\bar{S}^{b}$.

2. Sellers attain the same expected surplus $\bar{S}^{s}$.

3. The expected surpluses of buyers and sellers are identical and non-negative: $\bar{S}^{b}=\bar{S}^{s} \geq 0$.

4. The list $\omega$ solves the following program:

$$
\bar{S}^{s}=\max _{\left[\alpha,\left\{\left(q_{\varepsilon}, z_{\varepsilon}\right)\right\}_{\varepsilon \in[1, \bar{\varepsilon}]}\right]} \pi^{s}(\alpha) \int_{1}^{\bar{\varepsilon}}\left[z_{\varepsilon}-c\left(q_{\varepsilon}\right)\right] d F(\varepsilon)
$$

subject to

$$
\begin{aligned}
\bar{S}^{b} & =\pi^{b}(\alpha) \int_{1}^{\bar{\varepsilon}}\left[\varepsilon u\left(q_{\varepsilon}\right)-z_{\varepsilon}\right] d F(\varepsilon)-i \hat{z}, \\
\hat{z} & =\max \left\{z_{\varepsilon}\right\}_{\varepsilon \in[1, \bar{\varepsilon}]}, \text { and } \\
\alpha, q_{\varepsilon} & \geq 0 \text { for all } \varepsilon .
\end{aligned}
$$

Conditions 1 to 3 are straightforward. Buyers are free to choose the submarket they visit, and they have identical payoff functions (21), so they must attain the same expected surplus. The same is true for sellers. Moreover, for trade to occur there must be buyers and sellers present in the submarket so that individuals must be indifferent between the two trading roles, and these roles must be preferable to no trade. Condition 4 results from a combination of optimal behavior and competition among sellers when they post their price offers. According to this condition, sellers choose the offer that maximizes their expected surplus, taking as given the expected surplus $\bar{S}^{b}$ attained by buyers, and realizing that the ratio $\alpha$ is going to endogenously adjust so that (26) and (27) hold.

The price offers solving (25) to (28) are not restricted to ensure that the buyers' ex-post trade surplus (given by $\varepsilon u\left(q_{\varepsilon}\right)-z_{\varepsilon}$ ) is positive for all realizations of $\varepsilon$. This is because buyers are able to commit to the offer posted prior the realization of $\varepsilon$. A variation of our model in which such a commitment is not possible would introduce an extra individual rationality constraint in the program described by (25) to (28) stating that the buyers' ex-post trade surplus is non-negative for all $\varepsilon \in[1, \bar{\varepsilon}]$. We assume buyers are able to commit to the offers because the model delivers much sharper results. However, we derive the equations characterizing an equilibrium in the absence of this commitment for the case of private information in the Appendix 
Faig and Jerez: Inflation, Prices, and Information in Competitive Search

(see Statement 19).

A solution for the program described in (25) to (28) has the following two properties. First, buyers and sellers trade with probability one in any active submarket:

$$
\alpha=\pi^{b}(\alpha)=\pi^{s}(\alpha)=1 ;
$$

otherwise, the sellers' expected surplus in (25) could be easily increased while keeping the buyers' expected surplus in (26) constant. Second, the payments specified by the offer are uniform:

$$
z_{\varepsilon}=\hat{z} \text { for } \varepsilon \in[1, \bar{\varepsilon}] \text {. }
$$

To see this, notice that the sellers' expected surplus depends only on the buyers' average payment. In contrast, for a given average payment, a buyer prefers a smooth distribution of $\left\{z_{\varepsilon}\right\}_{\varepsilon \in[1, \bar{\varepsilon}]}$ because the opportunity cost of holding money depends on the maximum payment. Therefore, the optimal payments satisfy (30).

Substituting (29) and (30) into (25) yields

$$
\hat{z}=\bar{S}^{s}+\int_{1}^{\bar{\varepsilon}} c\left(q_{\varepsilon}\right) d F(\varepsilon) .
$$

Using (29) to (31), program described by (25) to (28) simplifies into

$$
\bar{S}^{s}=\max _{\left\{q_{\varepsilon}\right\}_{\varepsilon \in[1, \bar{\varepsilon}]}} \int_{1}^{\bar{\varepsilon}}\left[\frac{\varepsilon u\left(q_{\varepsilon}\right)}{1+i}-c\left(q_{\varepsilon}\right)\right] d F(\varepsilon)-\frac{\bar{S}^{b}}{1+i} .
$$

The equilibrium quantities that solve this program are given by the following firstorder condition:

$$
\varepsilon u^{\prime}\left(q_{\varepsilon}\right)=(1+i) c^{\prime}\left(q_{\varepsilon}\right) \text { for } \varepsilon \in[1, \bar{\varepsilon}] .
$$

This expression shows that, under full information, the inflation tax $(i>0)$ creates a proportional wedge $(1+i)$ between the marginal utility of consumption and the marginal cost of production in the same fashion as in economies with a cash-inadvance constraint. Also, for a given $i$, the quantity purchased increases with the type of buyer involved because $c$ is convex and $u$ is strictly concave. So, buyers with higher valuations purchase larger quantities.

To complete the characterization of a competitive search equilibrium, we need to determine $\bar{S}^{b}$ and $\bar{S}^{s}$. Since buyers and sellers attain the same expected surplus, (31) and (32) imply:

$$
\begin{aligned}
\bar{S}^{b} & =\bar{S}^{s}=\frac{\int_{1}^{\bar{\varepsilon}}\left[\varepsilon u\left(q_{\varepsilon}\right)-c\left(q_{\varepsilon}\right)\right] d F(\varepsilon)-i \hat{z}}{2} \\
& =\frac{1+i}{2+i} \int_{1}^{\bar{\varepsilon}}\left[\frac{\varepsilon u\left(q_{\varepsilon}\right)}{1+i}-c\left(q_{\varepsilon}\right)\right] d F(\varepsilon) .
\end{aligned}
$$


That is, buyers and sellers share equally the expected gains from bilateral trade, which are given by the expected bilateral trade surplus net of the cost of holding money. Furthermore, the strict concavity of $u$ and the convexity of $c$, together with $u^{\prime}(0)=\infty>c^{\prime}(0)$ ensure that both $\bar{S}^{b}$ and $\bar{S}^{s}$ are positive. This verifies that it is optimal for a buyer to demand $\hat{z}$ units of money, as claimed in the previous section.

We are ready for a formal definition of a monetary equilibrium:

$A$ monetary stationary equilibrium with full information is a vector of real numbers $\left(\alpha, \hat{z}, \bar{S}^{s}, \bar{S}^{b}\right)$ and a set of real functions $\left\{\left(q_{\varepsilon}, z_{\varepsilon}\right)\right\}_{\varepsilon \in[1, \bar{\varepsilon}]}$ that satisfy the system of equations: (29), (30), (31), (33), and (34).

The system of equations characterizing an equilibrium is recursive: (29) and (33) respectively determine $\alpha$ and $\left\{q_{\varepsilon}\right\}_{\varepsilon \in[1, \bar{\varepsilon}]}$, (34) determines $\bar{S}^{s}$ and $\bar{S}^{b}$, and (30) and (31) determine $\hat{z}$ and $\left\{z_{\varepsilon}\right\}_{\varepsilon \in[1, \bar{\varepsilon}}$. The existence of a unique equilibrium follows from our assumptions on $u$ and $c$ which guarantee a unique solution for this system of equations.

Under full information, equilibrium offers minimize the opportunity cost of the money balances held by buyers by having $z_{\varepsilon}$ identical for all $\varepsilon$. Buyers optimally choose an amount of money equal to this flat payment and spend all their cash whenever they meet a seller. At the Friedman rule $(i \rightarrow 0)$, the quantities of output traded are the efficient $q_{\varepsilon}^{*}$ that satisfy $\varepsilon u^{\prime}\left(q_{\varepsilon}^{*}\right)=c^{\prime}\left(q_{\varepsilon}^{*}\right)$. Inflation above the Friedman rule implies a welfare cost as it generates a wedge between the marginal utility of consumption and the marginal cost of production at night. The convexity of $c$ and the strict concavity of $u$ imply that $q_{\varepsilon}$ is a decreasing function of $i$. It is easy to see that $\hat{z}, \bar{S}^{b}$ and $\bar{S}^{s}$ also decrease with $i$ (from (31) and (34), respectively). An increase in the inflation rate above the Friedman rule then distorts the equilibrium allocation away from the first best, reducing the quantities purchased by all buyer types: $q_{\varepsilon}<q_{\varepsilon}^{*}$, which reduces the expected bilateral trade surplus at night. Sellers absorb part of the welfare loss by reducing the flat payment they charge buyers, and buyers' real money balances fall as a result.

The result that buyers make a flat payment in the night market whenever the opportunity cost of holding money is positive seems highly counterfactual. While we occasionally observe sellers charging flat fees (e.g. "all-you-can-eat" restaurants), these seem to be the exception rather than the rule. Therefore, beyond a theoretical illustration of the type of pricing incentives generated by inflation, we view this result as a reductio-ad-absurdum of assuming full information in the environment we analyze. In Section 4, we analyze the same environment when preference shocks are privately observed by buyers. Sellers do not post a flat payment in this case because such payment schemes are not incentive compatible. Clearly, if buyers pay the same for all realizations of $\varepsilon$ but receive more output when $\varepsilon$ is high, they have an incentive to claim they experienced the highest realization $\bar{\varepsilon}$ regardless of their true type. Under private information, the extreme flat-fee result then disappears 
Faig and Jerez: Inflation, Prices, and Information in Competitive Search

and the model predicts that sellers post increasing, non-linear pricing schemes instead (e.g., positive but decreasing per unit prices). This kind of pricing schemes are quite common in retail markets, where we observe quantity discounts that are either explicit or (most often) implicit in the packaging of products.

\section{Competitive Search with Private Information}

Consider the competitive search market described in the previous section, but suppose shocks are privately observed by the buyers who experience them. In this case, the offers posted by sellers must be incentive compatible. That is, buyers must have no incentives to lie about their type. The program described by (25) to (28) is then further restricted to satisfy the incentive compatibility constraint: ${ }^{12}$

$$
\varepsilon^{\prime} \in \arg \max _{\varepsilon \in[1, \bar{\varepsilon}]}\left[\varepsilon^{\prime} u\left(q_{\varepsilon}\right)-z_{\varepsilon}\right], \text { for all } \varepsilon^{\prime} \in[1, \bar{\varepsilon}] .
$$

As is standard, constraint (36) can be restated using the following well-known result. (See Mas-Colell, Winston and Green (1995) Proposition 23.D.2.)

Lemma 1 Let the ex-post trade surplus of a type- $\varepsilon$ buyer be defined as

$$
v_{\varepsilon} \equiv \varepsilon u\left(q_{\varepsilon}\right)-z_{\varepsilon} .
$$

A trading offer satisfies the incentive-compatibility constraint (36) if and only if $q_{\varepsilon}$ is non-decreasing in $\varepsilon$, and $v_{\varepsilon}$ satisfies

$$
v_{\varepsilon}-v_{1}=\int_{1}^{\varepsilon} \frac{\partial}{\partial x}\left[x u\left(q_{x}\right)-z_{x}\right] d x=\int_{1}^{\varepsilon} u\left(q_{x}\right) d x, \text { for all } \varepsilon \in[1, \bar{\varepsilon}] .
$$

Using Lemma 1, (29), and (37), the maximization program described by (25) to (28) with the restriction (36) can be restated as the following optimal control problem:

$$
\bar{S}^{s}=\max _{\left[\hat{z},\left\{\left(q_{\varepsilon}, v_{\varepsilon}\right)\right\}_{\varepsilon \in[1, \bar{\varepsilon}]}\right]} \int_{1}^{\bar{\varepsilon}}\left[\varepsilon u\left(q_{\varepsilon}\right)-c\left(q_{\varepsilon}\right)-v_{\varepsilon}\right] d F(\varepsilon)
$$

12 With private information, an offer is a direct revelation-mechanism that is incentive compatible. While direct revelation mechanisms can in principle be random, this can only be optimal if absolute risk aversion decreases with $\varepsilon$ (see Maskin and Riley (1984)). In our environment, random mechanisms are never used in equilibrium because absolute risk aversion is independent of $\varepsilon$. We therefore restrict to deterministic mechanisms $\left\{\left(q_{\varepsilon}, z_{\varepsilon}\right)\right\}_{\varepsilon \in[1, \bar{\varepsilon}]}$ without loss of generality. See, however, Shimer and Wright (2004) for a different competitive search environment with indivisibilities where random mechanisms are optimal. 
subject to

$$
\begin{aligned}
\bar{S}^{b} & =\int_{1}^{\bar{\varepsilon}} v_{\varepsilon} d F(\varepsilon)-i \hat{z}, \\
\varepsilon u\left(q_{\varepsilon}\right)-v_{\varepsilon} & \leq \hat{z} \text { for } \varepsilon \in[1, \bar{\varepsilon}], \\
\dot{v}_{\varepsilon} & =u\left(q_{\varepsilon}\right) \text { for } \varepsilon \in[1, \bar{\varepsilon}], \text { and } \\
q_{\varepsilon} & \text { is } \text { non-decreasing in } \varepsilon, \\
\hat{z}, q_{\varepsilon} & \geq 0 \text { for } \varepsilon \in[1, \bar{\varepsilon}] .
\end{aligned}
$$

The control variable of this problem is $q_{\varepsilon}$ and the state variable is $v_{\varepsilon}$. Using the Maximum Principle, the optimal path for the control variable $q_{\varepsilon}$ must satisfy the following equation (see the Appendix for the derivation):

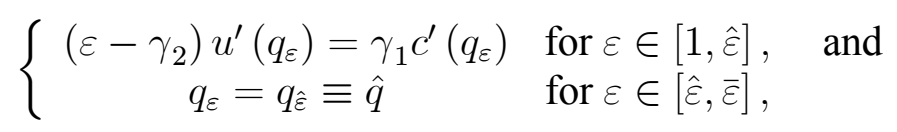

where $\gamma_{1}, \gamma_{2}$, and $\hat{\varepsilon}$ are positive numbers given by:

$$
\begin{aligned}
\gamma_{1} & =\frac{1+i}{1+2 i}, \\
\gamma_{2} & =\frac{i}{1+2 i}, \text { and } \\
\gamma_{1}+\frac{\gamma_{2}}{\bar{\varepsilon}} & =\frac{\hat{\varepsilon}}{\bar{\varepsilon}}+\frac{1}{2}\left[1-\left(\frac{\hat{\varepsilon}}{\bar{\varepsilon}}\right)^{2}\right] .
\end{aligned}
$$

Equation (45) shows that, with private information, the cash constraint becomes binding at a break-point shock $\hat{\varepsilon}$. Buyers with a realization of a preference shock higher than or equal to $\hat{\varepsilon}$ spend all their cash, while buyers with realizations lower than $\hat{\varepsilon}$ keep some unspent cash. It is useful to write $\hat{\varepsilon}$ as an implicit function of $i$ combining (46) to (48):

$$
\left(\frac{i}{1+2 i}\right) \frac{\bar{\varepsilon}}{\varphi}=\frac{(\bar{\varepsilon}-\hat{\varepsilon})^{2}}{2} .
$$

This equation implies that $\hat{\varepsilon}$ is a decreasing function the nominal interest rate $i$, with $\hat{\varepsilon}=\bar{\varepsilon}$ for $i \rightarrow 0$. The intuition for this result is simple. At the Friedman rule the cash constraint never binds because holding money it is not costly for buyers. Inflation above the Friedman rule induces buyers to reduce their real money balances, so the probability of being liquidity constrained becomes positive and increases with $i$. When the rate of growth of the money supply satisfies $\beta<\gamma<\beta(1+\bar{\varepsilon}) / 2$ (as we have assumed), there is a unique solution to (49) which satisfies $\hat{\varepsilon} \in(1, \bar{\varepsilon})$. So, there is always a subset of types who spend all their money and a subset of 
types who end up with some unspent cash in a monetary equilibrium. A monetary equilibrium with this property then emerges both at moderate and high inflation rates if individuals face a lot of uncertainty about their cash needs ( $\bar{\varepsilon}$ is high). If this uncertainty is low, equilibria of this kind emerge only at moderate inflation rates.

The other unknowns of the program described by (39) to (44) are determined as follows. The optimal path for the state variable $v_{\varepsilon}$ is implied by the differential equation (42) for a given initial value $v_{1}$. The optimal value of $\hat{z}$ is given by (41) with equality at the break-point $\hat{\varepsilon}$. The value $v_{1}$ in equilibrium is determined by the condition $\bar{S}^{s}=\bar{S}^{b}$. That is, $v_{1}$ must be such that

$$
\int_{1}^{\bar{\varepsilon}} v_{\varepsilon} d F(\varepsilon)-i \hat{z}=\int_{1}^{\bar{\varepsilon}}\left[\varepsilon u\left(q_{\varepsilon}\right)-c\left(q_{\varepsilon}\right)-v_{\varepsilon}\right] d F(\varepsilon) .
$$

Using (50), the equilibrium values of $\bar{S}^{b}$ and $\bar{S}^{s}$ are

$$
\bar{S}^{b}=\bar{S}^{s}=\frac{\int_{1}^{\bar{\varepsilon}}\left[\varepsilon u\left(q_{\varepsilon}\right)-c\left(q_{\varepsilon}\right)\right] d F(\varepsilon)-i \hat{z}}{2}
$$

since buyers and sellers share equally the expected gains from bilateral trade. It is easy to show that $\bar{S}^{b}$ and $\bar{S}^{s}$ are positive, which verifies that equation (18) holds also under private information. The argument is essentially the same as in the previous section and is thus omitted. Finally, the underlying payments $\left\{z_{\varepsilon}\right\}_{\varepsilon \in[1, \bar{\varepsilon}]}$ are calculated from (37).

The formal definition of the equilibrium is now the following:

$A$ monetary stationary equilibrium with private information is a vector of real numbers $\left(\alpha, \gamma_{1}, \gamma_{2}, \hat{\varepsilon}, \hat{z}, \bar{S}^{s}, \bar{S}^{b}\right)$ and a set of real functions $\left\{\left(q_{\varepsilon}, v_{\varepsilon}\right)\right\}_{\varepsilon \in[1, \bar{\varepsilon}]}$ that satisfy the system of equations: (29), (41) with equality at $\hat{\varepsilon}$, (42), (45), (46), (47), (49), (50), and (51).

The equilibrium is unique because the program described by (39) to (44) has a unique solution (see the Appendix).

With private information, equilibrium payments do not consist of a flat fee. Instead, payments must be increasing with the quantity of output purchased in order to satisfy the incentive-compatibility constraints generated by private information. This can be shown by calculating the derivative of the payment $z_{\varepsilon}$ relative to the output $q_{\varepsilon}$ in a transaction. Using the chain rule of differentiation together with (37), (42), (45), (46), and (47):

$$
\frac{d z_{\varepsilon}}{d q_{\varepsilon}}=\left(1-\gamma_{2}\right) c^{\prime}\left(q_{\varepsilon}\right)+\gamma_{2} u^{\prime}\left(q_{\varepsilon}\right) \text { for } \varepsilon \in(1, \hat{\varepsilon}) .
$$

This derivative is positive because $\gamma_{2} \in[0,1]$, and $c$ and $u$ are increasing functions. Equation(52) implies that the price schedule that maps the quantities of output pur- 
chased with the corresponding payments is

$$
\mathcal{Z}(q)=\gamma_{0}+\left(1-\gamma_{2}\right) c(q)+\gamma_{2} u(q)
$$

where $\gamma_{0}$ is a constant term that is determined endogenously as a function of $i$. Depending on the quantity purchased, sellers then charge a variable payment given by a convex combination of the cost of production and the utility of consumption of type 1 , and possibly a fixed transfer. (This transfer $\gamma_{0}$ adjusts with $i$ to ensure that buyers and sellers each receive half of the expected gains from bilateral trade). Writing (53) as $\mathcal{Z}(q)=c(q)+\gamma_{0}+\gamma_{2}[u(q)-c(q)]$, we see that sellers charge both a fixed and a variable markup. The total expected mark-up in equilibrium is $\bar{S}^{s}=\gamma_{0}+\gamma_{2} \int_{1}^{\bar{\varepsilon}}\left[u\left(q_{\varepsilon}\right)-c\left(q_{\varepsilon}\right)\right] d F(\varepsilon)$. This total markup falls when $i$ rises because, as we show below, the expected gains from bilateral trade fall. It can be shown that the fixed mark up $\gamma_{0}$ is maximal at the Friedman rule and that is minimal as $\gamma$ approaches the upper bound $\beta(1+\bar{\varepsilon}) / 2$. The opposite is true for the expected variable markup.

As in the full information model, the equilibrium is efficient at the Friedman rule. The cash constraint never binds when $i \rightarrow 0$, as we have already noted. Also, $\gamma_{1}=$ 1 and $\gamma_{2}=0$, so the quantities traded are efficient because they obey: $\varepsilon u^{\prime}\left(q_{\varepsilon}\right)=$ $c^{\prime}\left(q_{\varepsilon}\right)$. The price schedule in this case is given by $\mathcal{Z}(q)=\bar{S}^{s}+c(q)$, so that sellers charge a total payment equal to the cost of production plus a fixed transfer that covers their labor cost. This pricing scheme clearly leads to an efficient allocation because the cost of purchasing additional units is equal to the marginal cost of production (i.e., $\mathcal{Z}^{\prime}(q)=c^{\prime}(q)$ ).

The inefficiencies arising from the inflation tax are most easily identified by examining how the equilibrium price schedule changes when $i$ rises. In particular, it is easy to see that the slope of the price schedule falls with the nominal interest rate. The reason is that, as $i$ rises, the price schedule puts more weight on the concave function $u$ and less weight on the convex function $c$ because $\gamma_{2}$ increases. Using (45), (46), (47):

$$
\frac{d}{d i} \frac{d z_{\varepsilon}}{d q_{\varepsilon}}=\frac{1}{1+2 i} \frac{1-\varepsilon}{\varepsilon-\gamma_{2}} c^{\prime}\left(q_{\varepsilon}\right)<0 \text { for } \varepsilon \in(1, \hat{\varepsilon}) .
$$

Consequently, inflation not only curtails consumption due to a lack of liquidity for those buyers with a great desire to consume $(\varepsilon>\hat{\varepsilon})$, but it also increases consumption for those buyers with a low appetite for goods $(\varepsilon<\hat{\varepsilon})$. This key result is quite intuitive. As the nominal interest $i$ increases, the cost of being left with unspent money rises. Aware of this, sellers have an incentive to post price offers that imply a lower variability of payments, which is equivalent to posting flatter price schedules. With these flatter price schedules, the quantities purchased increase as long as $\varepsilon \in(1, \hat{\varepsilon})$ because the marginal cost of purchasing goods is lower. In particular, 
Faig and Jerez: Inflation, Prices, and Information in Competitive Search

with inflation rates above the Friedman rule, the marginal cost of purchasing goods is lower than the marginal cost of production. As a result, buyers purchase inefficiently high quantities as long as they are not liquidity constrained. To establish this formally we apply the Implicit Function Theorem to the system of equations (45) to (47):

$$
\frac{d q_{\varepsilon}}{d i}=\frac{\varepsilon-1}{(1+i)(1+2 i)} \frac{u^{\prime}\left(q_{\varepsilon}\right)}{\left(1-\gamma_{2}\right) c^{\prime \prime}\left(q_{\varepsilon}\right)-\left(\varepsilon-\gamma_{2}\right) u^{\prime \prime}\left(q_{\varepsilon}\right)}>0 \text {, for } \varepsilon \in(1, \hat{\varepsilon}] .
$$

Finally, it is easy to show that an increase in the nominal interest rate reduces the buyers' real money balances $\hat{z}$, as well as the quantity purchased $\hat{q}$ when the liquidity constraint binds.

\section{Empirical Implementation}

This section analyzes a quantitative version of the model. Our objective here is to highlight the empirical implications of the key insight we seek to model in this paper, that is, that sellers do not observe the preferences of a diverse clientele of buyers who hold precautionary balances. In this analysis, we show that both the model with full information in Section 2 and the model with incomplete information in Section 3 fit well the United States time series of the velocity of the circulation of money and nominal interest rates. However, the two models have markedly different predictions in some important dimensions. For example, the model with full information, as the standard cash-credit goods model, requires an extremely long payment period to fit the observed low velocity of the circulation of money, and it predicts that a moderate increase in the rate of inflation nearly collapses the output produced in the sector where money is essential for transactions. In contrast, the private information model does not generate these unrealistic predictions.

In the empirical implementation, we assume the same preferences as Lagos and Wright (2005), modified to allow for preference shocks:

$$
\begin{gathered}
\mathcal{U}^{b}\left(x_{t}, y_{t}, q_{t} ; \varepsilon_{t}\right)=B \ln \left(x_{t}\right)-y_{t}+\frac{\varepsilon_{t} q_{\varepsilon}^{1-\sigma}}{1-\sigma}, \sigma \in(0,1) \\
\mathcal{U}^{s}\left(x_{t}, y_{t}, q_{t}\right)=B \ln \left(x_{t}\right)-y_{t}-q_{t} .
\end{gathered}
$$

With these functional forms, the average commercial margin at night is increasing with the curvature parameter $\sigma$. In particular, the average commercial margin is $\sigma /(2-\sigma)$ at $i=0 .{ }^{13}$ Intuitively, if $U$ has a large curvature parameter $\sigma$, individuals

13 The derivation of this formula is lengthy and unrelated to the main issues of the paper, so it is not provided here. 
seek to consume small quantities often because marginal utility is strongly decreasing in $q_{\varepsilon}$. As a result, individuals require a large remuneration, in the form of a large commercial margin, to sacrifice their time to be sellers.

The previous literature offers little guidance about the distribution of preference shocks. So far, for analytical tractability, we have assumed that these shocks have been uniformly distributed. However, in this section we consider the following generalization to capture that large preference shocks are relatively rare. We assume now that with probability $p$ buyers have a "normal" desire to consume, in which case $\varepsilon$ equals one; and, with complementary probability, buyers experience a larger than normal desire to consume in which case $\varepsilon$ is uniformly distributed on the interval $(1, \bar{\varepsilon}]$. Algebraically, the distribution function is

$$
F(\varepsilon)=\left\{\begin{array}{cl}
p & \text { at } \varepsilon=1, \text { and } \\
\frac{1-p}{\bar{\varepsilon}-1}(\varepsilon-1) & \text { for } \varepsilon \in(1, \bar{\varepsilon}] .
\end{array}\right.
$$

Thus, the density for $\varepsilon \in(1, \bar{\varepsilon}]$ is constant and equal to

$$
\varphi=\frac{1-p}{\bar{\varepsilon}-1}
$$

Conveniently, this generalization of the distribution of shocks complicates relatively little the analytical solution of the model as shown in the Appendix.

To estimate the parameters of the model, we use annual observations on the velocity of the circulation of money and the short term commercial paper rate in the United States from 1892 to 2004. The velocity of the circulation of money is the ratio of GDP over M1*, defining M1* as M1 in circulation inside the United States. (See the Appendix for details and data sources.) Figure 1 displays both time series. For comparison purposes, it also displays the velocity of the circulation of M1. From 1892 to 2004, the velocity of the circulation of M1* changed widely. Until 1946, velocity seldom reached 4, but since then it has experienced a marked upward trend reaching levels close to 12 at the end of the sample. This upward trend is not explained well as a response to increasing interest rates because interest rates at the end of the sample are similar to those at the beginning, and yet velocity has tripled. Likewise, the upward trend in velocity is not explained well by GDP growth combined with a transactions elasticity of the demand for money lower than one because during the period when velocity exploded (the last 30 years of our sample) GDP grew more slowly than average. Our view is that the trend of velocity is due to an interaction between institutional changes and advances in information technology. Since our model abstracts away from these factors, we detrend both the velocity of the circulation of money and the commercial paper rate with a fourth power polynomial of time. ${ }^{14}$ The detrended variables are displayed in Figure 2.

14 We preserve the mean, and normalize time to go from minus one in 1892 to one in 2004. 
Faig and Jerez: Inflation, Prices, and Information in Competitive Search

Figure 1: Velocity of M1 and Interest Rates in the United States

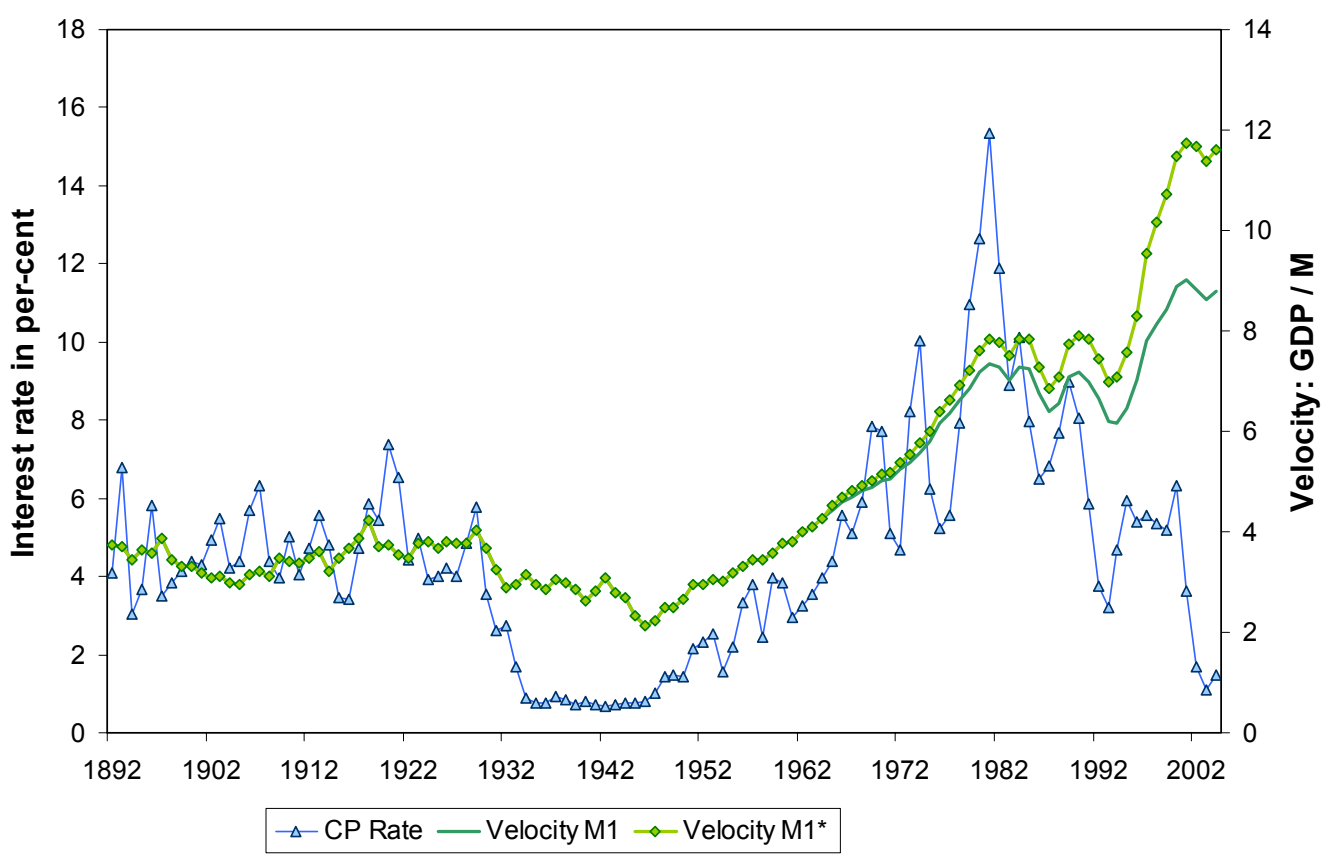

Figure 2: Detrended Velocity and Interest Rates

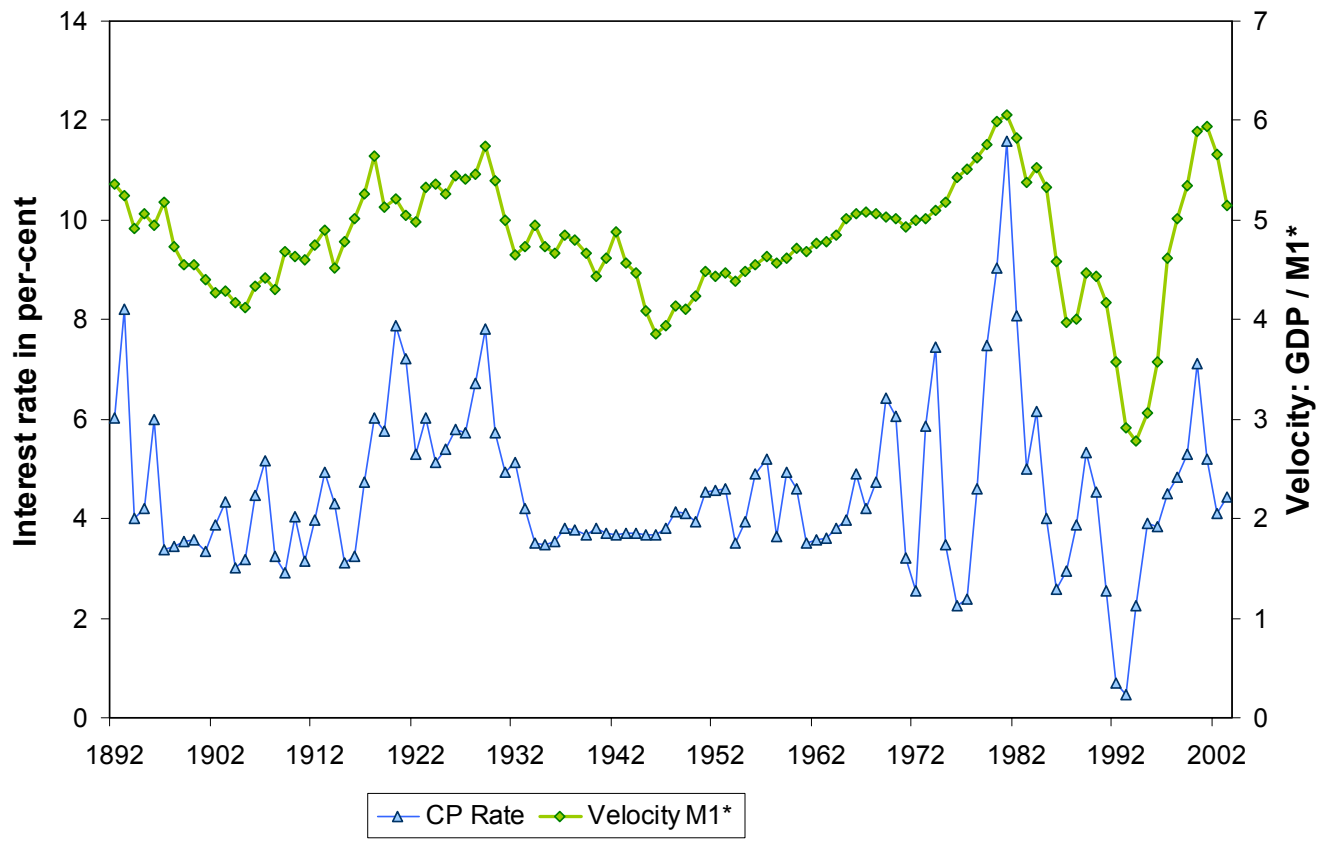

Published by The Berkeley Electronic Press, 2006 
The model's counterpart of the annual velocity of the circulation of money is aggregate expenditure multiplied by the number of periods in one year $(T)$ and divided by the demand for money: $\left[T \int_{1}^{\bar{\varepsilon}} \mathcal{Z}\left(q_{\varepsilon}\right) d F(\varepsilon)\right] / \hat{z}$. The counterpart of the commercial paper rate is the nominal interest on a personal bond traded during the day promising one dollar for the next day: $i=(\gamma-\beta) / \beta$. With quasi-linear preferences the velocity of the circulation of money in a given period depends only on the nominal interest rate for that period. Therefore, our analysis in Sections 2 and 3 carry through to a predictable time process of the money supply in which $\gamma$ and $i$ vary over time.

Historical data on velocity and interest rates do not allow for the identification of all the parameters of the model. Therefore, we restrict $\sigma$ to 0.453 to match the average commercial margin reported by the Bureau of the Census (www.census.gov/ $\mathrm{svsd} / \mathrm{www} /$ artstbl.htlm) (around 28 per cent). Likewise, we restrict $\bar{\varepsilon}$ to $12^{\sigma}$, so that quantities purchased vary from 1 to 12 . The results we report are not very sensitive to the particular values of these two parameters. However, with private information, it is important for the type of separating equilibrium we study to exist that $\bar{\varepsilon}$ is sufficiently high.

Table 2 reports the estimated parameters using nonlinear least squares for the following models: the full information model in Section 2 (model 1), the private information model in Section 3 (model 2), and the private information model with mass probability $p$ at $\varepsilon=1$ (model 3 ). This last model is introduced to capture that large expenditures are relatively rare, and this added realism allows us to fit the observed low velocity of circulation of money without relying on buyers having to wait unrealistically long periods to have an opportunity to make a purchase. In models 1 and 2, the parameters estimated are the number of periods in one year $(T)$ and the weight in the utility function of the goods traded during the day $(B)$. Loosely speaking, velocity increases with $T$, and the elasticity of velocity with respect to $i$ falls with $B$. To fit the low and highly elastic velocity observed in the United States, $B$ must be a large number and $T$ a low one. In particular, in the full information model the estimate of $T(0.41)$ implies that individuals take more than two years to spend their money. A similar effective payment period is also found in Lagos and Wright (2005) where individuals take on average two years to spend their money. In contrast, with private information individuals do not spend all their cash in each transaction. Hence, the private information model has the advantage that it fits equally well data with shorter payment periods. In model 2 with a uniform distribution of shocks, the estimate of $T$ is close to one. In model 3 , we successfully fit the model with a realistic payment period lasting one month $(T=12)$, in which case our estimate of $p$ implies that abnormally large preference shocks occur around once a year. 
Faig and Jerez: Inflation, Prices, and Information in Competitive Search

Table 2: Estimation of the Model

\begin{tabular}{|c|c|c|c|c|}
\hline \multicolumn{5}{|c|}{$\begin{array}{c}\text { Sample: Annual series United States } 1892-2004 \\
\text { Dependent variable: Detrended velocity }(\mathrm{GDP} / \mathrm{M} 1 *) \\
\text { Independent variables: Detrended commercial paper rate } \\
\text { Method: Non-linear least squares } \\
\sigma=0.435 \\
\bar{\varepsilon}=12^{\sigma}\end{array}$} \\
\hline & $T$ & $B$ & $p$ & $R^{2}$ \\
\hline Model 1 & $\begin{array}{c}0.41 \\
(0.07)\end{array}$ & $\begin{array}{r}31.50 \\
(3.97)\end{array}$ & $0^{*}$ & 0.40 \\
\hline Model 2 & $\begin{array}{c}0.98 \\
(0.30)\end{array}$ & $\begin{array}{l}17.86 \\
(4.58)\end{array}$ & $0^{*}$ & 0.42 \\
\hline Model 3 & $12^{*}$ & $\begin{array}{c}0.57 \\
(0.04)\end{array}$ & $\begin{array}{c}0.89 \\
(0.06)\end{array}$ & 0.42 \\
\hline
\end{tabular}

Note: Asterisks denote constrained values. Parentheses denote standard deviations of the estimates, which were calculated using the formula in Doan (2002) pp. 218-9 with $k=5$. This formula is robust to heteroscedasticity and autocorrelations of the error term up to five years apart.

Table 3 calculates the effect of a 10-per-cent increase in the annual rate of inflation from the Friedman rule $(i=0)$. The first row shows that the welfare cost of inflation is around 0.5 per cent of GDP in all three models. This similarity is not surprising since all three models have been estimated to predict the same money demand curve, and the welfare cost of inflation in these models is approximately the area below this curve. The second row shows that the three models have also similar predictions about the effect of inflation on GDP. However, the three models make markedly different predictions about the effect of inflation on the composition of GDP. Model 1 predicts that a 10-per-cent increase in inflation slashes the GDP produced at night by nearly 40 per cent, so that the fraction of GDP for which money is an essential medium of exchange drops from 10.5 per cent to 6.6 per cent. In contrast, these effects are much weaker in models 2 and 3. In particular, the effect of inflation on the composition of GDP is quite small in model 3, in which case the 10-per-cent increase in inflation reduces the fractions of GDP at night from 64.2 per cent to 62.9. Intuitively, the elasticity of the demand for money in model 3 is mainly due to a reduction in precautionary balances instead of sectorial shifts in expenditures. We cannot directly test this discriminating prediction because the $\mathrm{Na}$ tional Income Accounts do not calculate the composition of GDP according to the means of payment in transactions, but the consumption of nondurables and services 
(CNS) is a reasonable proxy for the transactions for which M1 is held. ${ }^{15}$ Therefore, the correlation between the ratio of CNS over GDP and the nominal interest rate is informative to assess the source of elasticity of the demand for money. If the high-interest elasticity observed in the United States is due to an increase in the fraction of cash goods, then the ratio CNS/GDP should be volatile and correlated with the commercial paper rate. This prediction is not supported by the data. The detrended CNS/GDP ratio is smooth and weakly correlated with the commercial paper rate. As a result, once the trend is removed, the OLS coefficient of CNS/GNP on the commercial paper rate is small $(-0.03)$ and not statistically significant. ${ }^{16}$ The predictions of the private information model 3 are in line with this observation.

Table 3: Effect of 10-per-cent Inflation

\begin{tabular}{lccc}
\hline \hline & Model 1 & Model 2 & Model 3 \\
\hline Effect of rising annual $i$ from 0 to 0.1: & & & \\
Welfare cost & 0.54 & 0.42 & 0.45 \\
Percentage change of GDP & -4.2 & -4.1 & -3.7 \\
Percentage change of GDP at night & -39.7 & -23.8 & -5.8 \\
Fraction of GDP at night for annual $i=0$ & 0.105 & 0.172 & 0.642 \\
Fraction of GDP at night for annual $i=0.1$ & 0.066 & 0.136 & 0.629 \\
\hline \hline
\end{tabular}

Note: The welfare cost is measured as the equivalent reduction of income as a percentage of GDP.

\section{Conclusion}

A precise modelling of private information in search-theoretic monetary models brings interesting new insights about the effects of inflation. In particular, we have constructed a competitive search monetary model where buyers are hit by privately observed preference shocks. The primary effect of inflation in the model is that it obstructs the role of prices in achieving an efficient allocation of goods. The equilibrium allocation is inefficient because individuals sometimes end up buying goods they value little, while at other times they lack the liquidity to buy goods they value much more.

The intuition for how inflation distorts the composition of consumption is as follows. Buyers have a precautionary motive for holding money because their cash

15 See Mankiw and Summers (1986) and Faig (1989).

16 We used United States annual data from 1929 to 2004. See the Appendix for the sources. 
needs are uncertain. The problem is that holding money is costly due to inflation. Aware of this, sellers try to attract buyers to their stores by posting price offers that reduce the precautionary money balances that buyers need to carry. Since they cannot observe the preferences of the buyers, sellers use non-linear price schedules to screen out different types of buyers. The key is that these non-linear price schedules become relatively flat as inflation rises (reducing the variance of payments and hence the need for precautionary balances). This means that the marginal cost of purchasing goods falls, and thus individuals purchase inefficiently high quantities as long as they are not cash constrained. Therefore, inflation ends up shifting consumption goods from cash-constrained individuals with high valuations for goods to individuals with low valuations who are not cash constrained.

We show that the model fits historical US data on velocity and interest rates. With the estimated parameters, we find that the welfare cost of inflation is approximately 0.5 per cent of GDP, which matches the area below the predicted money demand curve. While an empirical test of the many alternative models of demand for money is beyond the scope of this paper, we provide empirical evidence in support of the key feature we seek to capture in our model, namely that sellers do not observe the preferences of a diverse clientele of buyers who, as a result, hold precautionary balances. We have shown that this feature not only allows for a fit to United States data on velocity and interest rates, but also generates realistic implications about both the composition of output and the length of payment periods. 


\section{Appendices}

\section{Competitive Search Equilibrium with Private Information}

Since both (39) and (40) are monotonic in $v_{\varepsilon}$, the solution of (39) to (44) is the same as the solution of a dual program that maximizes (40) subject to (39) and the remaining constraints of the original program. In this Appendix, we solve this dual program in two stages. Stage 1 (Statements 1 to 13) solves for the program for a given Lagrange multiplier $\lambda$ associated with constraint (39), given $\hat{z}$ and $v_{1}$, and an exogenous output floor $\underline{q}$. Stage 2 (Statements 14 to 19) finds $\lambda, \hat{z}, v_{1}$, and $\underline{q}$ for a class of distribution functions which includes the uniform distribution.

1. Suppose $\lambda>1 / 2, \underline{q} \geq 0$, and $\hat{z}>\bar{\varepsilon} U(\underline{q})-v_{1}$ (these inequalities will hold for the endogenous values found in stage 2 of the proof if $i$ is sufficiently small). The terms of trade in a competitive search equilibrium with private preference shocks solve the following program: ${ }^{17}$

$$
J\left(\lambda, v_{1}, \hat{z}, \underline{q}\right)=\max _{\left\{q_{\varepsilon}, v_{\varepsilon}\right\}_{\varepsilon=1}^{\bar{\varepsilon}}} \int_{1}^{\bar{\varepsilon}}\left\{v_{\varepsilon}+\lambda\left[\varepsilon u\left(q_{\varepsilon}\right)-u\left(q_{\varepsilon}\right)-v_{\varepsilon}\right]\right\} \varphi d \varepsilon
$$

subject to

$$
\begin{gathered}
\dot{v}_{\varepsilon}=u\left(q_{\varepsilon}\right), \\
z_{\varepsilon} \equiv \varepsilon u\left(q_{\varepsilon}\right)-v_{\varepsilon} \leq \hat{z}, \\
q_{\varepsilon} \geq \underline{q}, \text { and } \\
v_{1} \text { given. }
\end{gathered}
$$

2. Program (60) to (64) is a standard optimal control problem where $q_{\varepsilon}$ is the control variable and $v_{\varepsilon}$ is the state variable. A solution to the program exists because the set of feasible paths is non-empty, bounded, with a feasible path for which the objective in (60) is finite. For example, the path $q_{\varepsilon}=\underline{q}$ for all $\varepsilon$ and $v_{\varepsilon}=v_{1}+(\varepsilon-1) u(\underline{q})$ is feasible, and with this path the objective in (60) is finite.

3. Suppose there is an interval $[a, b] \subseteq[1, \bar{\varepsilon}]$ of values of $\varepsilon$ where the inequality constraint (63) is binding, that is $q_{\varepsilon}=\underline{q}$ for $\varepsilon \in[a, b]$. Then (61) and (62) imply that in this interval $z_{\varepsilon}$ is constant and equal to $a U(\underline{q})-v_{a} \leq a u(q)-v_{1}$. Since $a \leq \bar{\varepsilon}$ and $\hat{z}>\bar{\varepsilon} u(\underline{q})-v_{1}$, constraint (62) is not binding in $[a, b]$. Therefore, constraints (62) and (63) never bind simultaneously.

17 The constraint $q_{\varepsilon}$ must be a non-decreasing function of $\varepsilon$ is omitted for the time being because as it will be seen it is not binding with our distribution of shocks. 
Faig and Jerez: Inflation, Prices, and Information in Competitive Search

4. Suppose there is an interval $[a, b] \subseteq[1, \bar{\varepsilon}]$ of values of $\varepsilon$ where the inequality constraint (62) is binding, that is $z_{\varepsilon}=\hat{z}$ for $\varepsilon \in[a, b]$. Then Statement 3 implies that in this interval $q_{\varepsilon}>\underline{q} \geq 0$, and so $u\left(q_{\varepsilon}\right)>0$. Hence, (61) and (62) imply that $q_{\varepsilon}$ is constant in the interval $[a, b]$.

5. Let $\varpi_{\varepsilon}$ denote the co-state variable associated with (61), and $\varsigma_{\varepsilon}$ and $\vartheta_{\varepsilon}$ be the Lagrange multipliers associated with (62) and (63), respectively. The Hamiltonian of the program (60) to (64) is:

$$
\begin{aligned}
\mathcal{H}= & v_{\varepsilon} \varphi+\lambda\left[\varepsilon u\left(q_{\varepsilon}\right)-c\left(q_{\varepsilon}\right)-v_{\varepsilon}\right] \varphi+\varpi_{\varepsilon} u\left(q_{\varepsilon}\right) \\
& +\varsigma_{\varepsilon}\left[\hat{z}-\varepsilon u\left(q_{\varepsilon}\right)+v_{\varepsilon}\right]-\vartheta_{\varepsilon}\left(\underline{q}-q_{\varepsilon}\right) .
\end{aligned}
$$

6. For the values of $\varepsilon$ such that (62) is not binding, the Hamiltonian (65) is strictly concave with respect to $q_{\varepsilon}$ (for these values $\varsigma_{\varepsilon}=0$ ) and linear (and so concave) with respect to $v_{\varepsilon}$. For the values of $\varepsilon$ such that (62) is binding, $q_{\varepsilon}$ is a constant (Statement 4). Therefore, the solution to the program (60) to (64) is unique; it is characterized by the first-order conditions that result from applying the Maximum Principle, and both $q_{\varepsilon}$ and $v_{\varepsilon}$ are continuous functions of $\varepsilon$.

7. The first-order condition with respect to the control variable $q_{\varepsilon}$ is $\left(\mathcal{H}_{q_{\varepsilon}}=\right.$ $0)$ :

$$
\left(\lambda \varphi-\varsigma_{\varepsilon}\right) \varepsilon u^{\prime}\left(q_{\varepsilon}\right)+\varpi_{\varepsilon} u^{\prime}\left(q_{\varepsilon}\right)=\lambda \varphi c^{\prime}\left(q_{\varepsilon}\right)-\vartheta_{\varepsilon} .
$$

The co-state variable must obey $\left(\mathcal{H}_{v_{\varepsilon}}=-\dot{\varpi}_{\varepsilon}\right)$ :

$$
\dot{\varpi}_{\varepsilon}=(\lambda-1) \varphi-\varsigma_{\varepsilon} .
$$

Finally, the transversality condition implies ${ }^{18}$ :

$$
\varpi_{\bar{\varepsilon}}=0 .
$$

Integrating (67) for an interval $[\varepsilon, \bar{\varepsilon}]$ and using (68), the value of the co-state variable $\varpi_{\varepsilon}$ is solved to obtain:

$$
\varpi_{\varepsilon}=(\lambda-1) \varphi(\varepsilon-\bar{\varepsilon})+\Sigma_{\varepsilon},
$$

where, to simplify the algebraic notation, we use the following definition:

$$
\Sigma_{\varepsilon} \equiv \int_{\varepsilon}^{\bar{\varepsilon}} \varsigma_{e} d e .
$$

18 The transversality condition is $\varpi_{\bar{\varepsilon}} v_{\bar{\varepsilon}}=0$. However, $v_{\bar{\varepsilon}}>0$ if $v_{1}>0$ given $U() \geq$.0 and (61). If $v_{1}=0$ still $v_{\bar{\varepsilon}}>0$. If $v_{\bar{\varepsilon}}=0$ then $v_{\varepsilon}=0$ for all $\varepsilon$ (as $v_{\varepsilon}$ is non-decreasing). But, this is impossible since the buyer's expected utility is strictly positive in equilibrium. 
Using (69), the first-order condition (66) is transformed into:

$$
\left[(2 \lambda-1) \varphi-\varsigma_{\varepsilon}\right] \varepsilon u^{\prime}\left(q_{\varepsilon}\right)=\left[(\lambda-1) \varphi \bar{\varepsilon}-\Sigma_{\varepsilon}\right] u^{\prime}\left(q_{\varepsilon}\right)+\lambda \varphi c^{\prime}\left(q_{\varepsilon}\right)-\vartheta_{\varepsilon} .
$$

8. Suppose there is an interval $[a, b] \subseteq[1, \bar{\varepsilon}]$ of values of $\varepsilon$ where the two inequality constraints (62) and (63) are not binding. Then the Kuhn-Tucker Theorem implies $\varsigma_{\varepsilon}=\vartheta_{\varepsilon}=0$ for $\varepsilon \in[a, b]$, so that the first-order condition (71) simplifies into

$$
\left(\varepsilon-\gamma_{2}\right) u^{\prime}\left(q_{\varepsilon}\right)=\gamma_{1} c^{\prime}\left(q_{\varepsilon}\right) \quad \text { for } \varepsilon \in[a, b],
$$

where

$$
\gamma_{1}=\frac{\lambda}{2 \lambda-1}, \text { and } \gamma_{2}=\frac{(\lambda-1) \bar{\varepsilon}-\Sigma_{b} \varphi^{-1}}{2 \lambda-1} .
$$

Since both $u^{\prime}\left(q_{\varepsilon}\right)$ and $c^{\prime}\left(q_{\varepsilon}\right)$ are strictly positive, $q_{\varepsilon}$ is strictly positive, and $\lambda>1 / 2$, (72) can only hold if $\varepsilon>\gamma_{2}$. The Implicit Function Theorem applied to (72) implies that $q_{\varepsilon}$ is an increasing function of $\varepsilon$ in the interval $[a, b]$. This property combined with (61), (62) and $u^{\prime}\left(q_{\varepsilon}\right) \geq 0$ implies that $z_{\varepsilon}$ is also increasing in the interval $[a, b]$.

9. Combining Statements $3,4,6$, and $8, z_{\varepsilon}$ is a non-decreasing continuous function for all $\varepsilon \in[1, \bar{\varepsilon}]$. Therefore, either (62) is never binding, or it is binding in an interval of high values of $\varepsilon:[\hat{\varepsilon}, \bar{\varepsilon}]$. In such an interval, Statement 5 implies that $q_{\varepsilon}$ is positive and constant: $q_{\varepsilon}=\hat{q}$ for $\varepsilon \in[\hat{\varepsilon}, \bar{\varepsilon}]$.

10. Combining Statements $3,4,8$, and $9, q_{\varepsilon}$ is a non-decreasing continuous function for all $\varepsilon \in[1, \bar{\varepsilon}]$. Therefore, either (63) is never binding, or it is binding in an interval of low values of $\varepsilon:\left[1, \varepsilon_{0}\right]$.

11. Statements 7 to 10 imply the following characterization of the optimal path of the control variable:

$$
\begin{gathered}
q_{\varepsilon}=\underline{q} \text { for } \varepsilon \in\left[1, \varepsilon_{0}\right] \text { if } \varepsilon_{0}>1, \\
\left(\varepsilon-\gamma_{2}\right) u^{\prime}\left(q_{\varepsilon}\right)=\gamma_{1} c^{\prime}\left(q_{\varepsilon}\right) \quad \text { for } \varepsilon \in\left[\varepsilon_{0}, \hat{\varepsilon}\right], \text { and } \\
q_{\varepsilon}=\hat{q} \quad \text { for } \varepsilon \in[\hat{\varepsilon}, \bar{\varepsilon}] \text { if } \hat{\varepsilon}<\bar{\varepsilon},
\end{gathered}
$$

where

$$
\gamma_{1}=\frac{\lambda}{2 \lambda-1}, \text { and } \gamma_{2}=\frac{(\lambda-1) \bar{\varepsilon}-\Sigma_{\hat{\varepsilon}} \varphi^{-1}}{2 \lambda-1} .
$$

The two real numbers $\varepsilon_{0}$ and $\hat{\varepsilon}$ obey: $1 \leq \varepsilon_{0} \leq \hat{\varepsilon} \leq \bar{\varepsilon}$.

12. If $\hat{\varepsilon}=\bar{\varepsilon}$ (condition (62) is never binding), then $\Sigma_{\hat{\varepsilon}}=0$. If $\hat{\varepsilon}<\bar{\varepsilon}$, the firstorder condition (71) can be simplified using (74) and (75) for $\hat{\varepsilon}$, to obtain

$$
\varsigma_{\varepsilon} \varepsilon=(2 \lambda-1) \varphi(\varepsilon-\hat{\varepsilon})+\Sigma_{\varepsilon}-\Sigma_{\hat{\varepsilon}} .
$$


Faig and Jerez: Inflation, Prices, and Information in Competitive Search

Since $\varsigma_{\varepsilon}=-\dot{\Sigma}_{\varepsilon},(76)$ is a differential equation. Its general solution is:

$$
\begin{aligned}
\varsigma_{\varepsilon} & =\frac{1}{2}(2 \lambda-1) \varphi+\frac{K}{\varepsilon^{2}}, \text { and } \\
\Sigma_{\varepsilon} & =\Sigma_{\hat{\varepsilon}}-\frac{1}{2}(2 \lambda-1) \varphi(\varepsilon-2 \hat{\varepsilon})+\frac{K}{\varepsilon} .
\end{aligned}
$$

The constant of integration $K$ can be determined using the condition $\varsigma_{\hat{\varepsilon}}=0$, so that

$$
K=-\frac{1}{2}(2 \lambda-1) \varphi \hat{\varepsilon}^{2} .
$$

Also, the definition (70) implies $\Sigma_{\bar{\varepsilon}}=0$. Therefore,

$$
\Sigma_{\hat{\varepsilon}}=\frac{\varphi \bar{\varepsilon}}{2}(2 \lambda-1)\left[1-2 \frac{\hat{\varepsilon}}{\bar{\varepsilon}}+\left(\frac{\hat{\varepsilon}}{\bar{\varepsilon}}\right)^{2}\right] .
$$

Combining (80) and (75), we obtain:

$$
\gamma_{1}+\frac{\gamma_{2}}{\bar{\varepsilon}}=\frac{\hat{\varepsilon}}{\bar{\varepsilon}}+\frac{1}{2}\left[1-\left(\frac{\hat{\varepsilon}}{\bar{\varepsilon}}\right)^{2}\right] .
$$

13. Conditional on $\varepsilon_{0}$ and $\hat{\varepsilon}$, the set of equations (74), (75), and (80) characterize the optimal path of the control variable $\left\{q_{\varepsilon}\right\}_{\varepsilon=1}^{\bar{\varepsilon}}$. The optimal path $\left\{v_{\varepsilon}\right\}_{\varepsilon=1}^{\bar{\varepsilon}}$ is obtained from (61) and (64). If interior, the optimal values of $\varepsilon_{0}$ and $\hat{\varepsilon}$ are obtained combining the interior first-order condition (72) with the constraints (63) and (62), respectively. The values of $\varepsilon_{0}$ and $\hat{\varepsilon}$ are at a corner solution if at $\varepsilon_{0}=1$ and/or $\hat{\varepsilon}=\bar{\varepsilon}$ the constraints (63) and (62) are satisfied together with the associated Kuhn-Tucker complementary conditions.

14. The Lagrange multiplier $\lambda$ is associated with constraint (39). Consider the following generalization of the uniform distribution: $\varepsilon=1$ with probability $p$, and $\varepsilon$ is uniformly distributed in the interval $[1, \bar{\varepsilon}]$ with probability $1-p$. For this generalized distribution, the values $\underline{q}, \lambda, \hat{z}$, and $v_{1}$ solve the following program:

$\max _{\left\{q_{1}, \underline{q}, \hat{z}, v_{1}, \lambda\right\}}(1-p) J\left(\underline{q}, \lambda, \hat{z}, v_{1}\right)+p\left\{v_{1}+\lambda\left[u\left(q_{1}\right)-c\left(q_{1}\right)-v_{1}\right]\right\}-i \hat{z}$

subject to (39) and

$$
q_{1} \geq \underline{q^{19}}
$$

\footnotetext{
19 The incentive-compatibility constraints imposed by the private information of shocks imply that at $\varepsilon=1$ the value of $v_{\varepsilon}$ is continuous and $q_{\varepsilon}$ is non-decreasing.
} 
15. The first-order interior conditions of program (82) can be written as follows:

$$
\begin{gathered}
(1-p) J_{\underline{q}}\left(\underline{q}, \lambda, \hat{z}, v_{1}\right) \geq 0, \text { with equality if } q_{1}>\underline{q}, \\
u^{\prime}\left(q_{1}\right)-c^{\prime}\left(q_{1}\right) \geq 0, \text { with equality if } q_{1}>\underline{q}, \\
i=(1-p) J_{\hat{z}}\left(\underline{q}, \lambda, \hat{z}, v_{1}\right), \text { and } \\
{\left[(1-p) J_{v_{1}}\left(\underline{q}, \lambda, \hat{z}, v_{1}\right)+p(1-\lambda)\right]=0 .}
\end{gathered}
$$

together with constraint (39).

16. Using the Envelope Theorem, (65), (70), and $\varphi=(\bar{\varepsilon}-1)^{-1}$, conditions (86) and (87) are transformed into:

$$
\begin{gathered}
i=(1-p) \Sigma_{\hat{\varepsilon}} \\
(1-p)(1-\lambda)+(1-p) \Sigma_{\hat{\varepsilon}}+p(1-\lambda)=0 .
\end{gathered}
$$

Therefore,

$$
\lambda=1+i .
$$

Conditions (88) and (90) combined with (73) implies that

$$
\gamma_{1}=\frac{1+i}{1+2 i}, \text { and } \gamma_{2}=\frac{i}{1+2 i} \frac{1-p \bar{\varepsilon}}{1-p}
$$

For $i>0$, (88) implies $\Sigma_{\hat{\varepsilon}}>0$, so that constraint (62) binds. Given $\gamma_{1}$ and $\gamma_{2}$, the value of $\hat{\varepsilon}$ is obtained from (81).

17. Define $q_{1}^{*}$ to be the solution to $u^{\prime}\left(q_{1}^{*}\right)=c^{\prime}\left(q_{1}^{*}\right)$. The value $q=q_{1}^{*}$ solves (82) because for this value (91) and (74) imply that $q_{\varepsilon}>q$ so that (83) is not

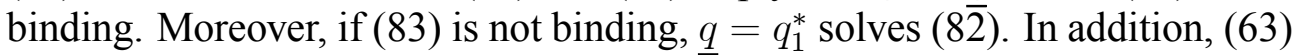
is never binding, so that $\varepsilon_{0}=1$. Equation (88) also implies for all $i>0$ that (62) binds, so that $\hat{\varepsilon}<\bar{\varepsilon}$.

18. In conclusion, the optimal path $\left\{q_{\varepsilon}\right\}_{\varepsilon=1}^{\bar{\varepsilon}}$ is characterized by $q_{1}=q_{1}^{*}$ together with (74), (81), (91), and $\varepsilon_{0}=1$. The inequalities assumed at the head of Statement 1 are satisfied because (90) implies $\lambda>1 / 2$. The assumptions about $u$ and $c$ imply $q_{1}^{*}>0$, so that $\underline{q}=q_{1}^{*}>0$. Finally, for $i=0$ (88) implies $\Sigma_{\hat{\varepsilon}}=0$, so that constraint (62) is never binding, so that continuity implies that for $i$ sufficiently small $\hat{z}>\bar{\varepsilon} U(\underline{q})-v_{1}$. In this case, the optimal value of $\hat{z}$ is $\hat{\varepsilon} u(\hat{q})-v_{\hat{\varepsilon}}$. Finally, the equilibrium value of $v_{1}$ is determined by the condition 
Faig and Jerez: Inflation, Prices, and Information in Competitive Search

$$
\bar{S}^{s}=\bar{S}^{b} \text {, that is } \int_{1}^{\bar{\varepsilon}} v_{\varepsilon} d F(\varepsilon)-i \hat{z}=\int_{1}^{\bar{\varepsilon}}\left[\varepsilon U\left(q_{\varepsilon}\right)-c\left(q_{\varepsilon}\right)-v_{\varepsilon}\right] d F(\varepsilon) .
$$

19. In the baseline model, the value of $\lambda$ in (90) is independent of $\bar{S}^{b}$ in (40) because utility is transferable (modifying $v_{1}$ ) at the rate 1 to $1+i$. If the timing of shocks is such that we must impose the ex-post individual rationality constraint: $v_{\varepsilon} \geq 0$ for $\varepsilon \in[1, \bar{\varepsilon}]$, then transfers from buyers to sellers must be such that $v_{1} \geq 0$. If this constraint is not binding, the competitive search equilibrium is the one characterized in previous statements because $v_{\varepsilon}$ is nondecreasing with $\varepsilon$. If $v_{1} \geq 0$ binds, (63) binds for a subset of types, who prefer not to purchase anything and to pay nothing, so $\varepsilon_{0}>1$ and $q_{\varepsilon}=z_{\varepsilon}=v_{\varepsilon}=0$ for $\left[1, \varepsilon_{0}\right)$. Equation (88) still holds, but (89) is now replaced by $1-\lambda+\Sigma_{\hat{\varepsilon}} \leq 0$, which yields the complementary condition for $v_{1} \geq 0$ to be binding. For $F$ uniform, a solution is easily found combining the values of $\gamma_{1}$ and $\gamma_{2}$ in (73) with (88) to obtain:

$$
\frac{\left(1-\gamma_{1}\right) \bar{\varepsilon}-\gamma_{2}}{2 \gamma_{1}-1}=\frac{i}{\varphi}
$$

Also, (74) implies $\varepsilon_{0}=\gamma_{2}$. In this case, the optimal solution $\left\{q_{\varepsilon}\right\}_{\varepsilon=1}^{\bar{\varepsilon}}$ is characterized by (74), (81) and (92) together with $v_{1}=0$, and $\varepsilon_{0}=\gamma_{2}{ }^{20}$

\section{Data Sources}

The interest rate is the short-term commercial paper rate. For 1892-1971, it is taken from Friedman and Schwartz (1982), Table 4.8, Column 6. For 1972-2004, it is taken from the DRI series FYCP90 (averaged).

Money is M1* = M1 - currency outside the country. M1 is the stock at the end of June of each year. For 1892-1928, the source of M1 is the United States Bureau of the Census (1965), Series X267. For 1929-1958, it is the series constructed by the St. Louis FED that extends backwards modern M1 http://research.stlouisfed.org/ aggreg. For 1959-2004, it is the DRI series FZM1. Currency in circulation abroad is from the FED Flow of Funds Table L-204 in the file ltab204d.prn downloaded from http://www.federalreserve.gov/releases/z1/current/data.htm.

For 1892-1928, GDP is calculated from the real GDP series in Kendrick (1961) and the implicit price deflator in Friedman and Schwartz (1982), Table 4.8, Column 4. For 1929-2004, it is from BEA NIPA Table 1.1.5 downloaded from www.bea. doc.gov/bea/dn/nipaweb. The same Table has data on consumption of nondurables and services.

20 If there is mass probability at $\varepsilon=1, \varepsilon_{0}$ is not necessarily equal to $\gamma_{2}$ and the equations characterizing the optimal path are substantially more complicated. 


\section{References}

Berentsen, Aleksander, Gabriele Camera, and Christopher Waller (2005), "Money, Credit, and Banking," IEW Working Paper No. 219.

Berentsen, Aleksander, and Guillaume Rocheteau (2004), "Money and Information," Review of Economic Studies, 71, 915-944.

Camera, Gabriele, and Johannes Winkler (2002), "International Monetary Trade and the Law of One Price," manuscript.

Doan, Thomas (2002), RATS version 5 User's Guide, Evanston, Illionois.

Ennis, Huberto M. (2005), "Search, Money, and Inflation under Private Information," manuscript.

Faig, Miquel (1989), "Seasonal Fluctuations and the Demand for Money," Quarterly Journal of Economics, 93, 847-861.

_ — (2004), "Divisible Money in an Economy with Villages," manuscript.

- - and Xiuhua Huangfu (2006), "Competitive Search in Monetary Economies," Journal of Economic Theory, forthcoming.

Faig, Miquel, and Belén Jerez (2005a), "A Theory of Commerce," Journal of Economic Theory, 122 (1), 60-99.

— - and — - (2005b), "Precautionary Balances and the Velocity of the Circulation of Money," Journal of Money, Credit, and Banking, forthcoming.

Friedman, Milton and Anna J. Schwartz (1982), Monetary Trends in the United States and the United Kingdom. Their Relation to Income, Prices, and Interest Rates 1867-1975, National Bureau of Economic Analysis, University of Chicago Press, Chicago, IL, and London, UK.

Guerrieri, Veronica (2005), "Efficiency of Competitive Search under Asymmetric Information," manuscript.

Kendrick, John W. (1961), Productivity Trends in the United States, Princeton University Press, Princeton, NJ.

Kiyotaki, Nobuhiro and Randall Wright (1989), "On Money as a Medium of Exchange," Journal of Political Economy, 97, 927-954.

— — and — _ (1991), "A Contribution to the Pure Theory of Money," Journal of Economic Theory, 53, 215-35.

Kocherlakota, Narayana (1998), "Money is Memory," Journal of Economic Theory, 81, 232-251.

Lagos, Ricardo, and Guillaume Rocheteau (2005), "Inflation, Output and Welfare," International Economic Review, 46 (2), 495-522. 
Faig and Jerez: Inflation, Prices, and Information in Competitive Search

Lagos, Ricardo, and Randall Wright (2005), "A Unified Framework for Monetary Theory and Policy Analysis," Journal of Political Economy, 113 (3), 463-484.

Mankiw, Gregory N., and Lawrence H. Summers (1986), "Money Demand and the Effect of Fiscal Policies," Journal of Money, Credit, and Banking, 18, 415-429.

Mas-Colell, Andreu, Michael Winston, and Jerry Green (1995), Microeconomic Theory, Oxford University Press, New York.

Maskin, Eric and John Riley (1984), "Monopoly with Incomplete Information," The Rand Journal of Economics, 15, 171-196.

Moen, Espen (1997), “Competitive Search Equilibrium," Journal of Political Economy, 105 (2), 385-411.

— — and Åsa Rosen (2004), "Incentives in Competitive Search Equilibrium and Unemployment Volatility," manuscript.

Montgomery, James (1991), "Equilibrium Wage Dispersion and Interindustry Wage Differentials," Quarterly Journal of Economics, 106 (1), 163-179.

Mussa, Michael and Harvey S. Rosen (1978), "Monopoly and Product Quality," Journal of Economic Theory, 18, 301-317.

Ostroy, Joseph M. (1973), "The Informational Efficiency of Monetary Exchange," American Economic Review, 63 (4), 597-610.

Peters, Michael (1991), "Ex-Ante Price Offers in Matching Games: Non-Steady States," Econometrica, 59 (5), 1425-1454.

Rocheteau, Guillaume, and Randall Wright (2003), "Inflation and Welfare in Models with Trading Frictions," manuscript.

- — and - - (2005), "Money in Search Equilibrium, in Competitive Equilibrium, and in Competitive Search Equilibrium," Econometrica, 73, 175-202.

Shi, Shouyong (1997), "A Divisible Search Model of Fiat Money," Econometrica, $65,75-102$.

Shimer, Robert (1996), "Contracts in a Frictional Labour Market," MIT manuscript.

- - and Randall Wright (2004), "Competitive Search with Asymmetric Information," manuscript.

United States Bureau of the Census (1965), The Statistical History of the United States from Colonial Times to the Present, Fairfield Publishers Inc., Stamford, Connecticut.

Wallace, Neil (2001), “Whither Monetary Economics?” International Economic Review, 42, 847-869.

Williamson, Stephen D. and Randall Wright (1994), "Barter and Monetary Ex- 
Advances in Macroeconomics, Vol. 6 [2006], Iss. 1, Art. 3

change Under Private Information,"American Economic Review, 84 (1), 104123. 